\title{
A Study of The Association of Impaired Glucose Metabolism in Patients with Newly Detected Rheumatoid Arthritis
}

\author{
${ }^{1}$ Dr G THIRUMAL, ${ }^{2}$ Dr S SENTHUR RAJA PANDIAN MD (Gen Med), DM (Neuro), \\ ${ }^{3}$ Dr M RAJKUMAR MD (Gen Med), ${ }^{4}$ Dr C DHARMARAJ MD ${ }^{(\mathrm{Gen} M e d), ~ D C H}$, \\ ${ }^{1}$ Senior Resident, Dept of Medicine, Govt Rajaji Hospital \& Madurai Medical College, Madurai \\ ${ }^{2}$ Assistant Professor of Medicine, Govt Rajaji Hospital \& Madurai Medical College, Madurai \\ ${ }^{3}$ Senior Assistant Professor of Medicine, Govt Rajaji Hospital \& Madurai Medical College, Madurai \\ ${ }^{4}$ Associate Professor of Medicine, Govt Rajaji Hospital \& Madurai Medical College, Madurai
}

\section{Introduction}

Rheumatoid arthritis is a systemic, autoimmune disorder that primarily manifests as chronic synovial inflammation of multiple joints. As in the general population, both Diabetes Mellitus (DM) and Insulin Resistance (IR) appear to be independent risk factors for atherosclerotic CVD in patients with RA. Over the last few decades it has become increasingly apparent that chronic activation of the immune system, as observed in the pathogenesis of RA, is associated with corollary changes in intermediary metabolism, potentially leading to increased risk of cardiovascular disease. There is evidence of association of multiple immune regulatory components (including tumour necrosis factor and interleukin-6) in RA, IR, and type 2 diabetes mellitus. Disease associated reduction in lean muscle mass and sedentary lifestyle likely further contribute to IR in patients with RA (2).

Impaired glucose metabolism (pre-diabetes and overt diabetes) is seen around $40-45 \%$ patients with RA. Hypertension is seen in more than $50 \%$ of patients with RA and metabolic syndrome seen around $40 \%$ of patients. Central obesity is seen in $>50 \%$ of patients.

Both impaired beta cell function and insulin resistance is associated with impaired glucose handling in patients with rheumatoid arthritis. Abdominal obesity and RA disease activity are determinants of insulin resistance in patients with rheumatoid arthritis. Age and disease activity is associated with reduced beta cell function.

Tumour necrosis factor, a critical inflammatory cytokine in chronic active RA, has detrimental effects on lean muscle mass, resulting in sarcopenia and a relative increase in body adipose tissue, a condition known as rheumatoid cachexia. Levels of adiponectin, an adipocytokine, an inversely related to adiposity and IR, and adiponectin exerts favourable effects on insulin sensitivity and atherosclerosis. Adiponectin production by adipose cells is reduced by exposure to TNF- $\alpha$, and low Adiponectin levels co-occur with characteristics of metabolic syndrome in patients with RA. Adipose tissue macrophages produce inflammatory cytokine, such as TNF-alpha and IL-6, thereby increasing inflammatory activity both locally and systemically. TNF-alpha can obstruct the bioactivity of the insulin by inhibiting tyrosine phosphorylation and subsequent activation of both the insulin receptor and insulin receptor substrate. This pivotal pro inflammatory cytokine also impedes insulinglucose-mediated uptake in skeletal muscle.

As with TNF-alpha, IL-6 appears to affect insulin-signalling pathways by diminishing the effect of insulin. Human adipocytes releases IL-6, and IL-6 production is increased in obesity, with higher secretion in visceral than subcutaneous tissue. Reduction of IL-6 levels by the administration of anti-IL6 antibodies increased insulin sensitivity.

It is necessary to find out impaired glucose metabolism in early stage because

1) Patients with RA are likely to have increased risk of subclinical atherosclerosis and cardiovascular disease

2) Chronic inflammation in RA leads to impaired glucose metabolism due to insulin resistance and impaired beta cell function

3) Both pre-diabetes and overt diabetes aggravate atherosclerosis

4) Controlling of inflammation may improve glycaemic control through enhanced pancreatic insulin secretion and peripheral insulin sensitivity

5) Good glycaemic control reduce the risk of atherosclerosis and cardiovascular disease.

\section{Aims And Objectives}


- To assess the prevalence of Impaired glucose metabolism ( pre-Diabetes and overt Diabetes ) in newly detected Rheumatoid arthritis patients

- To improve the long term survival of Rheumatoid arthritis patients by early detection of Impaired glucose metabolism and timely institution of treatment

\section{Rheumatoid arthritis}

\section{Review Of Literature}

Most common form of chronic inflammatory arthritis is Rheumatoid arthritis which is idiopathic in nature. It commonly presents with peripheral polyarthritis which is symmetric in nature. Rheumatoid arthritis can present with extra articular manifestations because of systemic nature of disease. Rheumatoid arthritis cause significant mortality and morbidity. Compared with general population, patients with Rheumatoid arthritis has short life expectancy. Mortality rate is two times higher than general population. Leading cause of death in patients with Rheumatoid arthritis is cardio vascular disease. Infection is second most common cause of mortality.

Because of chronic activation of inflammation in Rheumatoid arthritis leads to changes in glucose metabolism. It can be due to increased peripheral resistance or impaired beta cell function. Altered glucose metabolism accelerates atherosclerosis which leads to increased cardiovascular mortality and morbidity in rheumatoid arthritis patients. Chronic inflammation also alters the lipid profile. Metabolic syndrome is also common in patients with rheumatoid arthritis because of insulin resistance.

\section{Epidemiology}

It affects $0.5-1 \%$ of adult population. In African and American countries it is around $0.2-0.4 \%$. It has highest prevalence in Native Americans which is around $7 \%$.

It affects adults between 25 to 55 years with increasing incidence. Incidence decreases after 75 years of age. Females are more commonly affected than males. Female to male ratio is 3:1. Highest female to male ratio is seen in Latin American and African. It is 6-8:1\%.

Tumor necrosis factor production is enhanced by estrogen, which may be reason behind increased female prevalence.

\section{Genetic Considerations}

First-degree relative of a patient have risk of 2-10 times greater than general population. Most important alleles are located within the major histocompatibility complex. One-third of genetic risk resides ithin this locus. Most of this risk is associated with allelic variation in the HLA-DRB1 gene. HLA-DRB1*0401 is associated with high risk of disease. Alleles associated with moderate risk are *0101, *0404, *0901 and *1001. Most common alleles in Asians are $* 0405$, and $* 0901$. Several non-MHC- related genes also contribute.

\section{Joint involvement}

Joint stiffness is common presenting symptoms, which is more in early morning lasts around 1 hour and improves with physical activity. It affects small joints of hand and feet. It is symmetric in nature. Initially it can present as

1. Mono articular

2. Oligo articular or

3. Poly articular

\section{Commonly affected joints are}

1. Wrist

2. Metacarpo phalangeal joint

3. Proximal inter phalangeal joint

4. Metatarso phalangeal joint

Because of coexistent osteoarthritis distal inter phalangeal joint can be involved. Radiological evidence of temporo mandibular joint involvement is common. But it does not cause any functional significance. One of the dramatic complication of Rheumatoid arthritis atlanto-axial subluxation which leads to compressive myelopathy. Thoracic and lumbar spines are usually not involved in RA. Damage to joint and soft tissues leads to chronic irreversible deformity.

1. Swan neck deformity - Hyperextension of PIP Flexion of DIP

2. Boutonniere deformity - Flexion of PIP Hyperextension of DIP

3. Z line deformity - Subluxation of first MCP Hyperextension of first inter phalangeal joint

4. Ulnar deviation - Subluxation of MCP Subluxation of PIP to volar side of hand

DOI: $10.9790 / 0853-150907108134 \quad$ www.iosrjournals.org $\quad 109 \mid$ Page


5. Piano-key movement of Ulnar styloid - Subluxation of distal ulna

6. Flat foot - Pes planovalgus due to involvement of mid tarsal joints.

\section{Constitutional symptoms:}

Much more common than the joint symptoms. Rule out systemic vasculitis or infection if temperature > $101 \mathrm{~F}$.

Subcutaneous nodules:

They are generally benign in nature. It occurs in the late course of disease. It affects $30-40 \%$ of patients. It is firm and non-tender. Commonly occur over bony prominences which is adherent to periosteum and tendons.

Lung, pleura, peritoneum and pericardium are also affected by rheumatoid nodules.

\section{Sjogren's syndrome:}

Rheumatoid arthritis is important cause of secondary Sjogren's syndrome. It affects around $10 \%$ of patients with rheumatoid arthritis

\section{Pulmonary Manifestation}

1. pleural disease -Most common pulmonary manifestation. It presents as pleuritic chest pain, dyspnea and pleural effusion. Pleural effusions are exudative in nature. Pleural fluid sugar $<30 \mathrm{mg} \%$.

2. Interstial lung disease - carries poor prognosis.

Presents as dry cough and dyspnea.

3. Pulmonary Nodules -Solitary or multiple.

4. Respiratory bronchiolitis

5. Bronchiectasis

6. Caplan's Syndrome - Nodules and pneumoconiosis after exposure to silica.

\section{Cardiac manifestations:}

It can involve pericardium, myocardium and endocardium. Though pericardium is the most common site of involvement clinically manifests in less than $10 \%$ of patients.

Cardiomyopathy can result from myocarditis or coronary artery disease. Commonest valvular abnormality is mitral regurgitation. Restrictive cardiomyopathy can result from deposition of amyloid.

\section{Vasculitis:}

It occurs in patients with long standing disease. Affects less than $1 \%$ of patients.

Cutaneous signs are petechiae, purpura, digital infarcts, gangrene, livedo reticularis and vasculitic ulcer.

It rarely presents as sensorimotor poly neuropathy.

\section{Hematologic manifestations:}

1. Normocytic normochromic anemia- severity of anemia correlate with degree of inflammation.

2. Platelet- usually elevated because of acute phase reaction. Rarely immune- mediated thrombocytopenia will be present.

3. Felty's syndrome - rare. Presents as triad of neutropenia, splenomegaly and nodular RA. It occurs in late stages of disease.

4. T cell large granular lymphocyte leukemia- due to indolent growth of LGL (Large granular lymphocyte) cells. It occurs in early stages of rheumatoid arthritis.

5. Lymphoma- fourfold risk of lymphoma. Diffuse large B-cell lymphoma is most common histologic type.

Osteoporosis- Inflammatory mediated activation of osteoclasts leads to generalized osteoporosis. Other factors contributing to osteoporosis are immobility and steroid abuse.

Hypoandrogenism - Testosterone, Dehydroepiandrosterone and Luteinizing hormone levels are lower in postmenopausal women and men with RA. Chronic inflammation leads to low testosterone level. Controlling of inflammation improves testosterone level.

\section{Diagnosis}

Acr-Eular 2010 classification criteria now is used to diagnose RA. Main aim of revising older 1987 ACR classification criteria is to diagnose RA patients at early stages and introduction of disease modifying therapy at early stages. Serum anti-cyclic citrullinated antibodies is included in newer criteria which is more specific for RA than RF. Rheumatoid nodules and radiographic joint damage is not included in newer criteria 
because both of changes occurring in late stages of RA. This criteria is applicable to newly presenting patients. They must have at least one joint involvement with definite clinical synovitis.

\section{Rheumatoid factor:}

Seronegative patients have less extra-articular manifestations and better prognosis compared to seropositive patients. Three isoforms of RF is occurring in serum of RA patients IgM, IgG and IgA. Commonly measured in laboratories is IgM isotype. Sensitivity of RF is $75-80 \%$. RA can't be excluded by negative RF.

About $1-5 \%$ of health population is positive for RF. RF is also positive in other connective tissue diseases and chronic infections like

1. Primary Sjogren's disease,

2. SLE (systemic lupus erythematosus),

3. Type II mixed essential cryoglobulinemia

4. Subacute bacterial endocarditis,

5. Chronic hepatitis B and C.

Classification Criteria For Rheumatoid Arthritis

\begin{tabular}{|c|c|c|c|}
\hline & & & SCORE \\
\hline \multicolumn{2}{|l|}{ JOINT INVOLVEMENT } & 1 large joint & 0 \\
\hline & & 2-10 large joints & 1 \\
\hline & & $1-3$ small joints & 2 \\
\hline & & 4-10 small joints & 3 \\
\hline & & $>10$ joints ( at least 1 small joint) & 5 \\
\hline \multirow[t]{3}{*}{ SEROLOGY } & & Negative RF and negative Anti-CCP & 0 \\
\hline & & Low positive $\mathrm{RF}$ or anti-CCP ( $\leq 3$ times) & 2 \\
\hline & & High positive RF or anti-CCP $(>3$ times $)$ & 3 \\
\hline ACUTE-PHASE & & Normal CRP and ESR & 0 \\
\hline RECTANTS & & Abnormal CRP and ESR & 1 \\
\hline DURATION & $\mathrm{OF}$ & $<6$ Weeks & 0 \\
\hline SYMPTOMS & & $\geq 6$ Weeks & 1 \\
\hline & & & \\
\hline & & 21 & \\
\hline
\end{tabular}

Anti-ccp:

It is more specific than RF.

Sensitivity is $75-80 \%$

Specificity is $95 \%$.

It is helpful to differentiate RA from other inflammatory arthritis in early stages. Patient who are positive for Anti-CCP have poor prognosis. Patients who are negative for one test (RF or Anti-CCP) may be positive for other test so it is complementary to go with both tests.

\section{Synovial fluid analysis}

It is inflammatory in nature with WBC count between 5000 to 50000 per cubic micro liter. Predominant cell type is neutrophil. RF, anti-CCP antibodies and immune complexes are also found in synovial fluid.

\section{Joint imaging:}

Plain X-ray is commonly used but MRI is sensitive than Pain X-ray in early stages. Common X-ray findings are

1. Juxta articular osteopenia,

2. Soft tissue swelling,

3. Symmetric joint space loss

4. Subchondral bone erosions

5. Joint subluxation.

Periarticular osteopenia is earliest radiographic finding. 
MRI- has greater sensitivity to early bone and bone marrow changes as well as synovitis and joint effusions. One of the early sign of inflammatory joint disease is bone marrow edema which can be easily picked up by MRI. Limiting factors are availability and cost.

USG can be used to detect bony erosions in accessible joints. Synovitis is also reliably detected by USG. It has advantages of lack of radiation, portability and low cost.

DAS28 (Disease Activity Scoring - 28):

DAS28 to assess improvement and progression of RA. It is a composite measure. It includes four parameters

1. Number of joints showing tenderness

2. Number of joints showing swelling

3. ESR or CRP

4. Subjective assessment of disease activity

\section{Joints to be assessed}
1. $\mathrm{MCP}$
2. PIP
3. Wrist
4. Elbow
5. Shoulder
6. Knee

Ankle and MTP is not included. Values range from 2.0 to 10.0

\begin{tabular}{|l|l|}
\hline SOCRE & DISEASE ACTIVITY \\
\hline$>5.1$ & \\
\hline & High disease activity \\
\hline 5.1 to 3.2 & Moderate disease activity \\
\hline & \\
\hline 3.2 to 2.6 & Low disease activity \\
\hline & \\
\hline$<2.6$ & Remission \\
\hline & \\
\hline
\end{tabular}

\section{Pathoegenesis of impaired glucose metabolism in patients with rheumatoid arthritis:}

\section{Rheumatoid cachexia:}

Increasing in central obesity is important risk factor for insulin resistance and metabolic syndrome. Elevation of TNF-alpha due to chronic activation of inflammation leads to decrease in lean body mass resulting in sarcopenia (1). There is redistribution of adipose tissue resulting central obesity. There is little or no weight loss. In spite of central obesity and sarcopenia, Body mass index calculated by BMI may be normal. It affects more than $50 \%$ patients of RA. Women are more prone to Rheumatoid Cachexia than men (2). Controlling of inflammation leads to decrease in obesity and increasing lean body mass.

\section{Adipose tissue:}

Adipose tissue is one of the important organ to store excess energy. Now it is recognized that adipose tissue is not a passive organ which can produce many important adipocytokines and inflammatory mediators. Adipose tissue regulate metabolism in other tissues by production of this adipocytokines and play an important role in propagation and initiation IR (3). Major adipocytokines and inflammatory mediators are

1. Adiponectin,

2. Leptin,

3. Resistin

4. visfatin

5. IL6

6. $\mathrm{TNF}-\alpha$

Low grade inflammation is induced by excess accumulation of lipid in adipose tissue. This leads to macrophage infiltration in adipose tissue. Inflammatory cytokines produced by this macrophages augment the inflammation both systemically and locally. Pro inflammatory cytokines is produced by liver also in response to cytokines from adipose tissue. 


\section{tnf- $\square$ (tumor necrosis factor):}

Major cytokine in RA is TNF- $\alpha$. It plays major role in induction of insulin resistance in the following ways

1. Induction of rheumatoid cachexia

2. By inhibiting tyrosine phosphorylation of insulin receptors block the effects of insulin (4).

3. In skeletal muscles block the insulin mediated glucose uptake (5).

4. Decrease adiponectin production (6).

5. Increase resistin production

IL- 6 another important cytokine in RA. Insulin resistance is induced in the same way as TNF- $\alpha$ (7).

Other cytokines elevated in RA is IL-2 and IL-17 (8).

\section{Leptin:}

Leptin produced by adipocytes. It plays role in glucose metabolism by 1 . Decreasing insulin secretion,

\section{Improving insulin sensitivity.}

In chronic inflammatory conditions like RA, There is elevation of CRP. CRP induce leptin resistance by blocking receptor binding.

It also has atherogenic effects by

1. Induction of endothelial dysfunction,

2. Stimulation of inflammatory reaction,

3. Oxidative stress,

4. Reduction of Paraxonase activity,

5. Platelet aggregation,

6. Smooth muscle cells modification (9).

\section{Adiponectin:}

It has following favourable effects

1. Anti inflammatory,

2. Anti atherogenic,

3. Antidiabetic properties (10).

Production of adiponectin by adipocytes is decreased by TNF-aand other inflammatory cytokines which leads to insulin resistance, dyslipidemia and metabolic syndrome.

\section{Resistin:}

In contrast to other adipokines which are mainly produced by adipocytes, macrophages and monocytes of peripheral blood produce Resistin (11). TNF- $\alpha$ induce expression of Resistin gene in mononuclear cells. It has

1. Pro inflammatory properties - up-regulate the TNF- $\alpha$ and IL-6 of mononuclear cells of peripheral blood (12).

2. Induce hepatic IR by increased hepatocellular production of TNF- $\alpha$ and IL-6. VISFATIN (colony enhancing factor of pre-B-cell):

TNF- $\alpha$ and interleukin-6 increase visfatin production. High

levels of visfatin is associated with hyperglycemia and insulin resistance (13).

\section{Lipotoxicity:}

Beta cell function is impaired by adipokines and excess non esterified fatty acids which released by enlarged adipose cells. Steroids in high dose also impair beta cell activity (19).

\section{Vitamin d:}

Vitamin D deficiency in patients with RA is associated with hyperlipidemia and metabolic syndrome. Supplementation of vitamin D improves dyslipidemia and decrease metabolic syndrome (14).

Finally it is concluded that patient with RA has high risk of impaired beta cell function and insulin function which potentially leads to impaired glucose metabolism and acceleration of atherosclerosis. 
Diabetes Mellitus: Diagnosis of impaired glucose tolerance and diabetes mellitus done with ADA-2014 guidelines

\begin{tabular}{|l|l|l|l|l|}
\hline & & Normal glucose & Pre-diabetes & Diabetes mellitus \\
\hline & & tolerance & & \\
\hline & & & & \\
\hline Fasting & plasma & $<100 \mathrm{mg} / \mathrm{dl}$ & $100-125 \mathrm{mg} / \mathrm{dl}$ & $\geq 126 \mathrm{mg} / \mathrm{dl}$ \\
\hline glucose & & & & \\
\hline & & & & \\
\hline 2-hour & plasma & $<140 \mathrm{mg} / \mathrm{dl}$ & $140-199 \mathrm{mg} / \mathrm{dl}$ & $\geq 200 \mathrm{mg} / \mathrm{dl}$ \\
\hline glucose & & & & \\
\hline & & & $5.7-6.4 \%$ & $\geq 6.5 \%$ \\
\hline HbA1C & & $<5.6 \%$ & & \\
\hline & & & & \\
\hline
\end{tabular}

Etiological classification of Diabetes mellitus:

1. Type 1 diabetes (Immune mediated / idiopathic),

2. Type 2 diabetes (Insulin resistance/ Insulin deficiency),

3. Other specific types of diabetes- Genetic defects of beta cell development or function, genetic defects in insulin action, disease of exocrine pancreas, Endocrinopathies, Drug or chemical induced, infections and other genetic syndromes.

4. Gestational diabetes mellitus.

\section{Diabetes related complications:}

\section{Microvascular:}

1. Eye disease Retinopathy, Macular edema.

2. Neuropathy

Sensory and motor (mono- and polyneuropathy), Autonomic.

Nephropathy

Albuminuria,

Declining renal function.

\section{Macrovascular:}

1. Coronary heart disease,

2. Peripheral arterial disease,

3. Cerebrovascular disease.

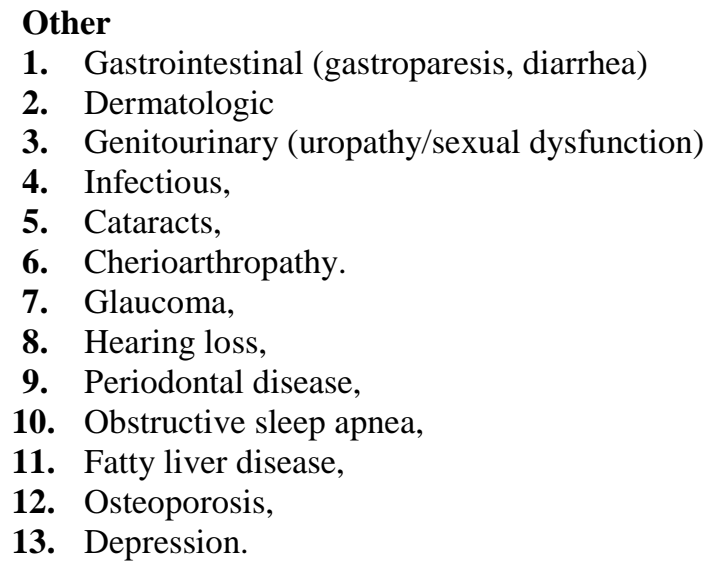

\section{Acute complications of diabetes mellitus:}

\section{DKA}

Relative or absolute insulin deficiency, Counter regulatory hormone xcess.

2. Hyperglycemic Hyperosmolar state (HHS) Relative insulin deficiency, Inadequate fluid intake.

Compared with DKA, patients with HHS has lower levels of counter regulatory hormones.

\section{Metabolic syndrome:}

(Syndrome X / insulin resistance syndrome)

Main underlying pathology of metabolic syndrome is insulin resistance. Metabolic syndrome is clustering of risk factors of cardiovascular disease including 
1. Central obesity,

2. Hypertension,

3. High triglycerides,

4. Low HDL levels.

Metabolic syndrome affects around $25 \%$ of adult population. They have two fold higher risk of death from cardiovascular disease and three fold from stroke. Risk of developing type 2 DM is fivefold compared to general population. They are also increased risk of

1. Fatty liver disease,

2. Hepatocellular carcinoma,

3. Intrahepatic cholangiocarcinoma,

4. Chronic kidney disease,

5. Polycystic ovary syndrome,

6. Obstructive sleep apnea,

7. Hyperuricemia and gout

There are five definitions for the MS. Most commonly used are

1. National cholesterol education program (NCEP/ATPIII),

2. International Diabetes Federation (IDF). NCEP:ATPIII 2001 Three or more of the following

\begin{tabular}{|c|c|c|c|c|}
\hline 1. & Central & obesity: & waist & $>102 \mathrm{~cm}$ (Male) \\
\hline & \multicolumn{2}{|c|}{ circumference } & & $>88 \mathrm{~cm}$ (Female) \\
\hline 2. & \multicolumn{2}{|c|}{ Triglyceride level } & & $>150 \mathrm{mg} / \mathrm{dl}$ \\
\hline & \multicolumn{2}{|c|}{ Or specific medication } & & \\
\hline \multirow{3}{*}{3.} & & & & \\
\hline & $\mathrm{HDL}$ & & & $<40 \mathrm{mg} / \mathrm{dl}$ (Male) \\
\hline & \multicolumn{2}{|c|}{ Or specific medication } & & $<50 \mathrm{mg} / \mathrm{dl}$ (Female) \\
\hline \multirow[t]{2}{*}{4.} & \multicolumn{2}{|c|}{ Hypertension } & & $\mathrm{SBP}>130 \mathrm{mmHg}$ \\
\hline & \multicolumn{2}{|c|}{ Or specific medication } & & $\mathrm{DBP} \geq 85 \mathrm{mmHg}$ \\
\hline 5. & \multicolumn{2}{|c|}{ Fasting plasma glucose } & & $>100 \mathrm{mg} / \mathrm{dl}$ \\
\hline & \multicolumn{2}{|c|}{ Or specific medication Or } & & \\
\hline \multicolumn{5}{|c|}{ previously diagnosed type $2 \mathrm{DM}$} \\
\hline & & & & \\
\hline & & & 34 & \\
\hline
\end{tabular}

1. A study was conducted by Karin L.G. Svenson et al., at 1988 in 14 untreated active rheumatoid arthritis patients. Compared with healthy controls, the patients had impaired glucose handling and enhanced insulin response $(p<0.01)$. Impaired glucose handling is found to be due to insulin resistance. Normalization of inflammatory activity with treatment improved insulin resistance and normalized glucose metabolism (15).

2. A study was conducted in Sweden at 1987 in the department of general medicine by Karin L.G. Svenson in 45 untreated rheumatoid arthritis patients. In the patient group, the basal serum insulin concentration $(p<$ $0.001)$ and the maximum insulin response to glucose loading $(\mathrm{p}<.01)$ were significantly higher. The rine output of cortisol and catecholamines was normal. So stress reaction can't be reason for impaired glucose metabolism (16).

3. A study was conducted by Lundqvist at 1987 in 42 patients with RA. Changes in glucose metabolism was monitored after institution of antirheumatic therapies. A reversal of glucose handling to normal was observed in patients treated with prednisolone $20 \mathrm{mg}$ daily $(\mathrm{n}=16, \mathrm{p}<.001)$, chloroquine $(\mathrm{n}=7)$, penicillamine $(\mathrm{n}=4)$, Azathioprine and cyclophosphamide $(\mathrm{n}=7)(17)$.

4. A study was conducted in South Africa at 2005 by Patrick H. Dessein et al., to identify factors that regulate glucose metabolism in RA patients. Insulin resistance and beta cell function is assessed in 94 RA patients. More insulin resistance is seen in patients with high grade inflammation (hsCRP $>1.92 \mathrm{mg} /$ liter) than low grade inflammation. Predictors of insulin resistance are abdominal obesity and disease activity. Disease activity and age is associated with impaired beta cell function. The cumulative use of glucocorticoids and ACE inhibitors or ARB was associated with enhanced beta cell function (18).

5. A study was conducted in 2002 by Sharma et al., effect of ACE inhibitors / ARBs in the prevention of Type 2 DM. Differentiation of adipocytes may be promoted by blockade of renin-angiotensin system which may be result in improved insulin activity. Decreased storage of excess calories in the pancreas reduce lipotoxicity which improves insulin secretion (20). 
6. A study was conducted by V. R. Da Cunha et al., in 2012 which includes 283 patients and 226 controls. Metabolic syndrome is seen in $39 \%$ of RA patients ( $\mathrm{p}<.001)$. Metabolic syndrome is seen only in $19 \%$ of controls.

When compared with controls increased prevalence of elevated blood sugar, waist circumference, and fasting blood sugar is seen in RA patients. RA

patients with MS has significantly high DAS-28 score (3.59 \pm 1.27 versus

$3.14 \pm 1.53 \mathrm{p}=.01)$ than those without MS (21).

7. A study was conducted in 2011 by C. S. Crowson et al., which includes 1214 non RA patients without CV disease and 232 RA patients without overt CV disease. MS, elevated blood pressure and waist circumference is significantly higher in RA patients (22).

8. In 2009 study was conducted in 400 RA patients by T. E. Toms et al., controlling of inflammation with methotrexate therapy was independently associated with reduced with risk to suffer MS. Prevalence of MS in 398 RA patients is $40.1 \%$ (23).

9. A study conducted by Chung et al., in 154 RA patients and 85 controls, increased risk of having higher coronary artery calcification score is seen in RA patients with MS (24).

10. Seriolo et al., conducted a study in 38 RA patients during follow up 24 of week improvement in HOMA / QUICKI seen in patients treated with Etanercept / Infliximab (25).

11. A study conducted by Tam et al., in 2007 in 19 RA patients treatment with Infliximab improves insulin sensitivity and lipid profile (26).

\section{Treatment of rheumatoid arthritis:}

Drugs used in the treatment of RA are

1. NSAIDs,

2. Glucocorticoids,

3. Conventional DMARDs

4. Biological DMARDs.

Anti-tnf agents:

1. The benefits of treatment with $\mathrm{TNF} \alpha$ antagonists as a class appear to extend beyond control of joint disease activity.

2. With prolonged anti-TNF treatment the partial restoration of metabolic function and alleviation of IR are becoming increasingly evident (27) (28).

Classical drugs are infliximab, Etanercept, Adalimumab.

Anti-TNF therapy carries risk of reactivation of latent TB, bacterial and fungal infections.

\section{Anakinra:}

The recombinant form of the naturally occurring IL-1 receptor antagonist. Due to high rate of serious infections it should not be combined with an anti-TNF drug.

\section{Abatacept:}

- $\quad$ It inhibits the co-stimulation of T cells by blocking CD28-CD80/86 interactions.

- $\quad$ It also inhibit the function of antigen-presenting cells by reverse signaling through CD80 and CD86.

\section{Rituximab:}

- $\quad$ Chimeric monoclonal antibody directed against CD20.

- It carries risk of progressive multifocal leukoencephalopathy.

\section{Tocilizumab:}

- Humanized monoclonal antibody directed against soluble and membrane forms of IL-6 receptor.

\section{Tofacitinib:}

- $\quad$ Small-molecule inhibitor that primarily inhibits JAK1 AND JAK3.

\section{Materials and methods:}

\section{Study population:}

This study is to be conducted in 50 newly detected Rheumatoid arthritis patients attending Rheumatology CLINIC at Govt Rajaji hospital, Madurai. 
Inclusion criteria:

Newly detected Rheumatoid arthritis patients according to ACR-EULAR criteria

2010 not on treatment.

\section{Exclusion criteria:}

Patients with

1. Previously known Diabetic patients

2. Family H/o DM

3. Patients on drugs impairing glucose metabolism

4. Conditions associated with impaired glucose tolerance such as

- Endocrinopathies

- Disease of exocrine pancreas

- Infections

- $\quad$ Genetics syndromes like Down's syndrome, Turner's syndrome

Increased prevalence of Impaired Glucose metabolism in patients with newly detected Rheumatoid arthritis.

The following information collected from patients who attended the Rheumatologic clinic for Rheumatoid arthritis in the form of Age, Sex, H/O Diabetes, Family H/O Diabetes, Duration of symptoms, Anthropometry measurements, Biochemical parameters [ Rheumatoid factor, ESR, CRP], Complication of Rheumatoid arthritis.

I excluded the patient with Family H/O diabetes, H/O overt diabetes, those on drugs impairing glucose metabolism, those on treatment for Rheumatoid arthritis and conditions associated with impaired glucose metabolism.

Random blood glucose, fasting plasma glucose, 2-hours plasma glucose in OGTT, urine sugar and fasting lipid profile is done in all patients.

NCEP:ATPIII 2001 criteria is used to define metabolic syndrome.

ADA, 2014 guidelines is used to define pre-diabetes and diabetes. Impaired glucose metabolism includes both pre-diabetic and diabetic.

Laboratory investigations Random blood glucose Fasting plasma glucose Two-hours plasma glucose in ogtt rine sugar Fasting lipid profile Erythrocyte sedimentation rate C- reactive protein Rheumatoid factor Design of study:

Observational study.

Period of study:

4 months (june 2015 to september 2015)

Collaborating departments:

Department of Pathology

Department of Biochemistry

Department of Microbiology

Ethical clearance: obtained

Consent: individual written and informed consent.

Analysis: statistical analysis.- chi square

Conflict of interest: nil

Financial support: nil

Participants:

50 newly detected Rheumatoid arthritis patients attending Rheumatology clinic at Govt Rajaji hospital, Madurai.

\section{Statistical metthods:}

The data collected during the study was formulated into a master chart in Microsoft office excel and statistical analysis was done with help of computer using statistical software package SPSS V.17 for windows. Using this software, frequencies, range, mean, standard deviation and ' $p$ 'were calculated through Student ' $t$ ' test, One way ANOVA, Pearson Correlation and Chi square test. P value of $<0.05$ was taken as significant.

\section{Results}

\section{Gender Distribution Of Ra}


A Study Of The Association Of Impaired Glucose Metabolism In Patients With Newly....

\begin{tabular}{|l|l|l|}
\hline Gender & No of cases & Percentage \\
\hline Male & 12 & 24 \\
\hline Female & 38 & 76 \\
\hline Total & 50 & 100 \\
\hline
\end{tabular}

Gender Distribution Of Ra

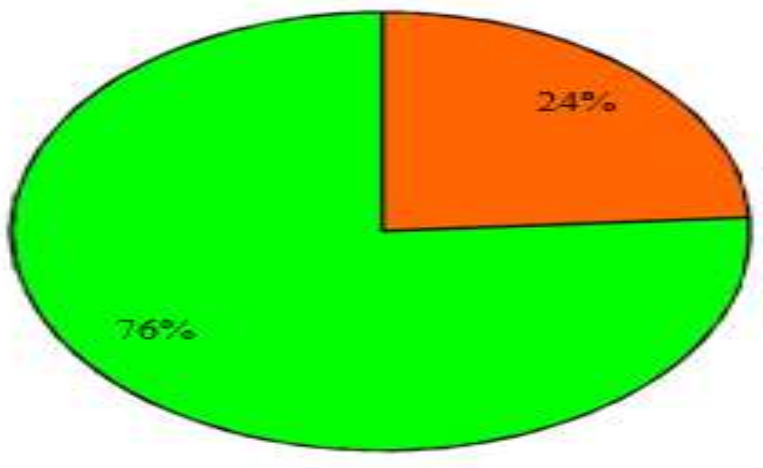

$\square$ Male $\square$ Female

In our study, male constituted nearly $24 \%(\mathrm{n}=12)$ and female $76 \%(\mathrm{n}=38)$.

This study shows RA is more common in female than in male $(\mathrm{p}<0.001)$ which is statistically significant. Female to male ratio is 3:1.

Age Distribution Of Ra

\begin{tabular}{|l|l|l|l|}
\hline \multicolumn{2}{|l|}{ Age in years } & Frequency & Percentage \\
\hline$<$ & 35 & 8 & 16 \\
\hline $36-45$ & 45 & 18 & 36 \\
\hline$>$ & 24 & 48 \\
\hline Total & 50 & 100 \\
\hline
\end{tabular}
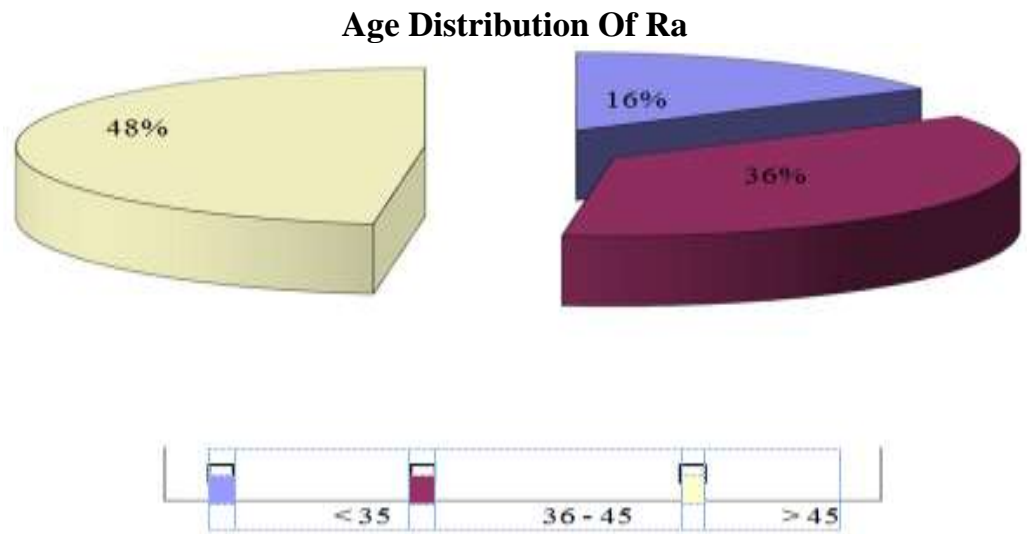

In our study among 50 patients, $16 \%(\mathrm{n}=8)$ of patients were less than 35 years, $36 \%(\mathrm{n}=18)$ of patients are between $36-45$ years and $48 \%(n=24)$ of patients are $>45$ years. It shows that incidence of RA increasing with age. Majority of patients were above 45 years.

Age (years)

Rheumatoid Factor

\begin{tabular}{|l|l|l|}
\hline Rheumatoid factor & Frequency & Percentage \\
\hline Positive & 44 & 88 \\
\hline Negative & 6 & 12 \\
\hline Total & 50 & 100 \\
\hline
\end{tabular}




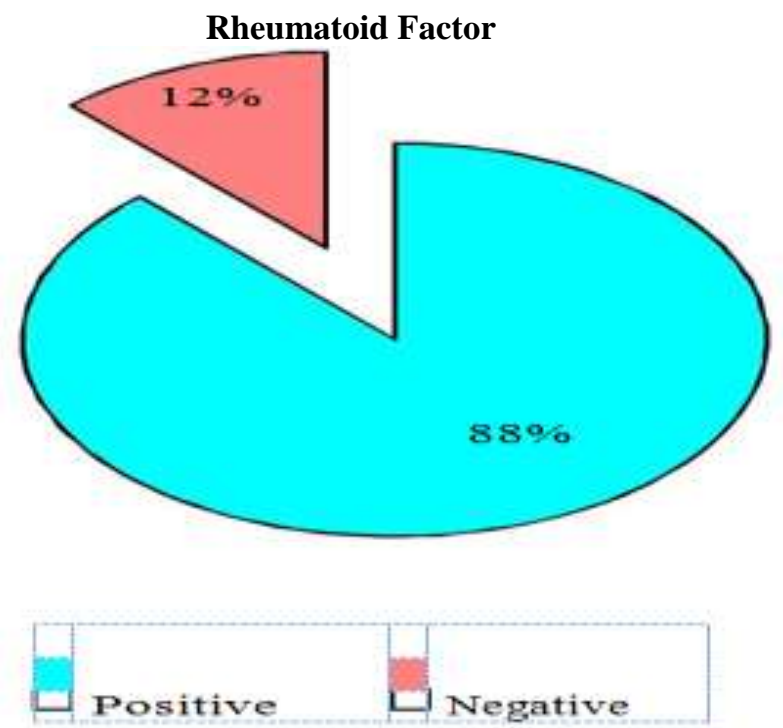

In our study among 50 patients, $88 \%(\mathrm{n}=44)$ of patients were Rheumatoid factor positive and $12 \%$ $(n=6)$ of patients were Rheumatoid factor negative. So sensitivity of Rheumatoid factor in our study is $88 \%$. Most patients were RF positive which is statistically significant $(\mathrm{p}<0.001)$.

\begin{tabular}{|l|l|l|}
\multicolumn{2}{c}{ Obesity In Ra Patients } \\
\hline Obesity & Frequency & Percentage \\
\hline Non obese & 16 & 32 \\
\hline Obese & 34 & 68 \\
\hline Total & 50 & 100 \\
\hline
\end{tabular}

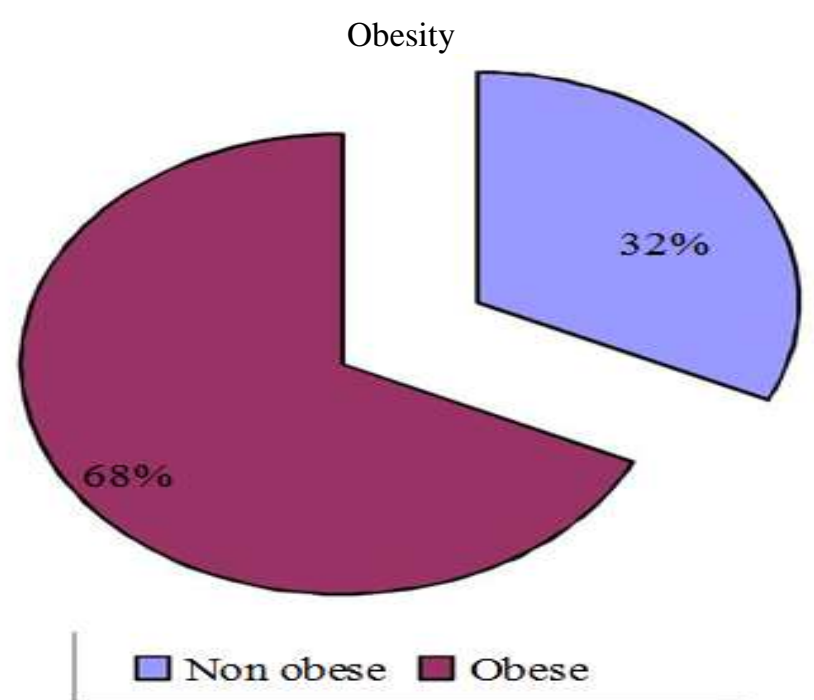

In our study, $68 \%(\mathrm{n}=34)$ of patients were obese $(\mathrm{p}<0.005)$ and $32 \%(\mathrm{n}=16)$ of patients were non obese. Hence statistically significant number of RA patients had central obesity.

Gender Distribution Of Obesity

\begin{tabular}{|l|l|l|l|l|}
\hline BESITY VS & \multicolumn{2}{|l|}{} & \multicolumn{2}{l|}{} \\
\hline GENDER & \multicolumn{2}{|l|}{ FREQUENCY } & \multicolumn{2}{l|}{ PERCENTAGE } \\
\hline & MALE & FEMALE & MALE & FEMALE \\
\hline OBESE & 8 & 26 & 67 & 68 \\
\hline NON OBESE & 4 & 12 & 33 & 32 \\
\hline TOTAL & 12 & 38 & 100 & 100 \\
\hline
\end{tabular}




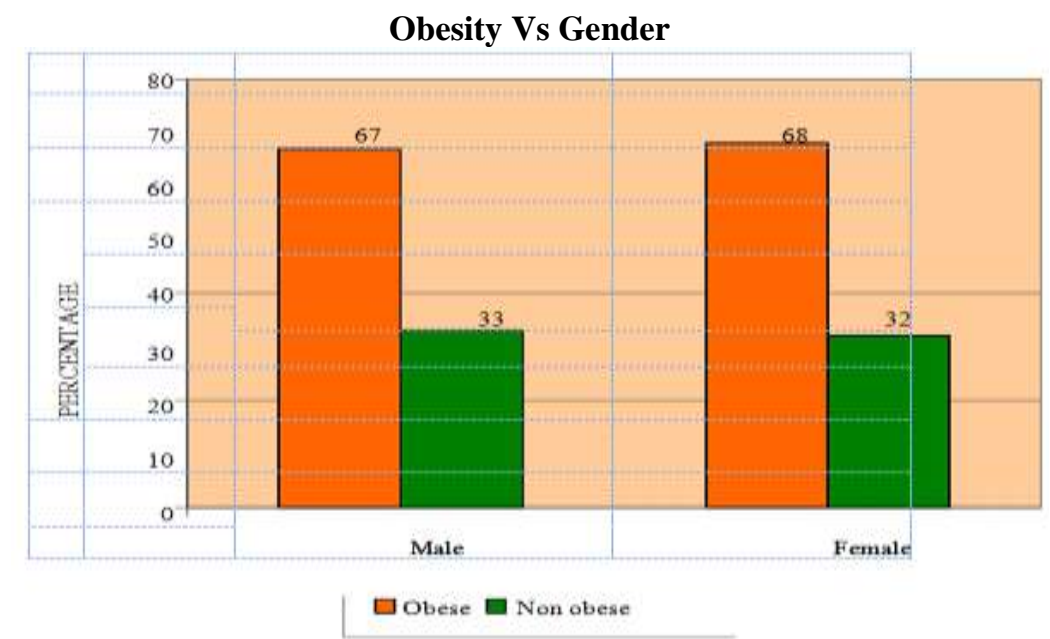

In our study among 12 male patients, $67 \%(n=8)$ male were obese and among 38 female patients, $68 \%$ $(\mathrm{n}=26)$ were obese. Both male $(\mathrm{p}<0.008)$ and female $(\mathrm{p}<0.005)$ RA patients had significant obesity. Female Patients had slightly high prevalence of obesity.

\begin{tabular}{|c|c|c|c|c|c|c|}
\hline \multicolumn{7}{|c|}{ Age Distribution Of Obesity } \\
\hline \multirow{3}{*}{$\begin{array}{l}\text { OBESITY VS } \\
\text { AGE }\end{array}$} & & & & & & \\
\hline & & \multicolumn{2}{|c|}{ FREQUENCY } & & \multicolumn{2}{|c|}{ PERCENTAGE } \\
\hline & & & & & $35-45$ & \\
\hline & $<35$ & $35-45$ & $>45$ & $<35$ & YERAS & $>45$ \\
\hline & YEARS & YEARS & YEARS & YEARS & & YEARS \\
\hline OBESE & 4 & 12 & 18 & 50 & 67 & 75 \\
\hline NON OBESE & 4 & 6 & 6 & 50 & 33 & 25 \\
\hline TOTAL & 8 & 18 & 24 & 100 & 100 & 100 \\
\hline
\end{tabular}

In our study among 8 patients less than 35 years, $50 \%(n=4)$ of patients were obese and among 18 patients between 35-45 years, $67 \%(\mathrm{n}=12)$ of patients were obese. Among 24 patients greater than 45 years, 75 $\%(\mathrm{n}=18)$ of patients were obese. Patients in the age group of $35-45$ years $(\mathrm{p}<0.008)$ and $>45$ years $(\mathrm{p}<0.001)$ had significant obesity. Prevalence of obesity is increasing with age

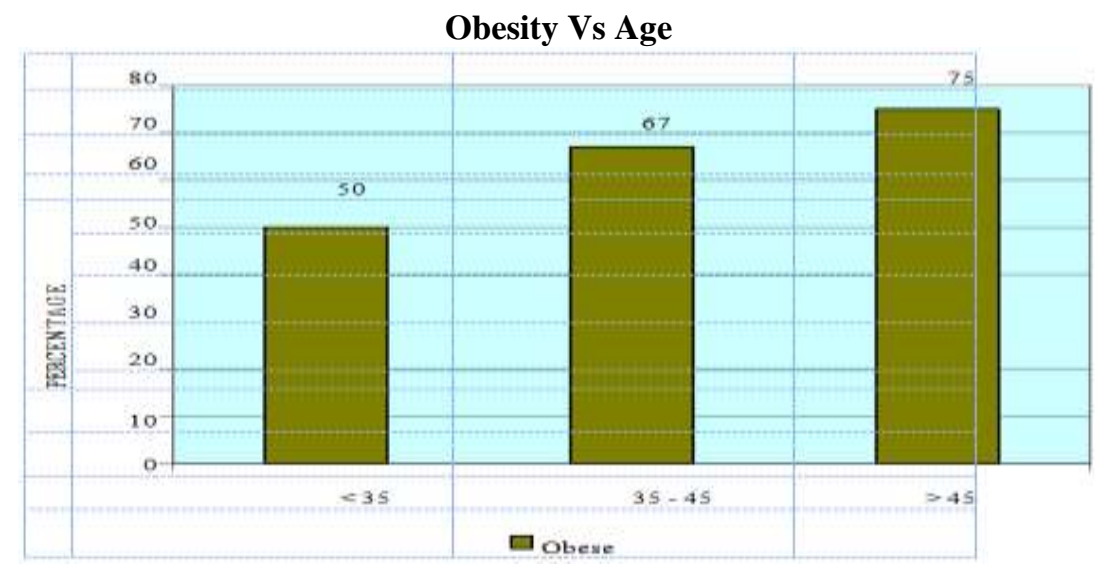

Hypertension In Ra

\begin{tabular}{|l|l|l|}
\hline HYPERTENSION & FREQUENCY & PERCENTAGE \\
\hline YES & 32 & 64 \\
\hline NO & 18 & 36 \\
\hline Total & 50 & 100 \\
\hline
\end{tabular}




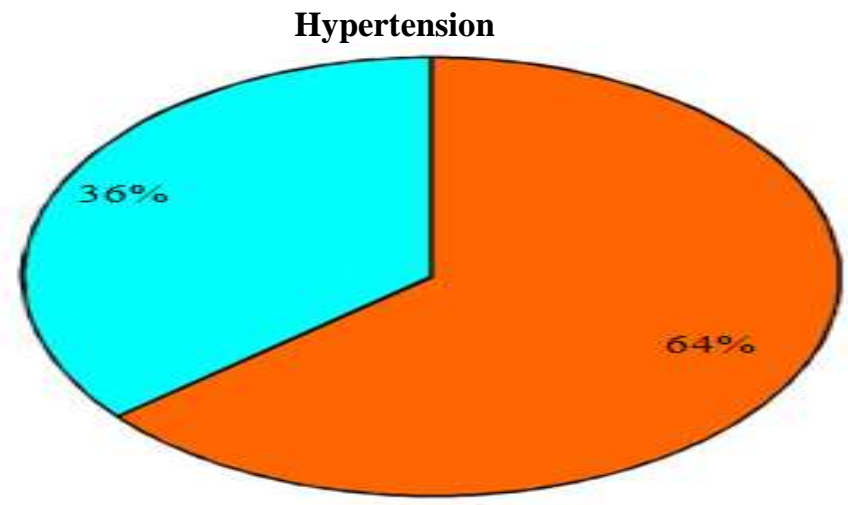

$\square$ HTN $\square$ Normal

In our study among 50 patients, $64 \%(n=32)$ of patients were hypertensive and $36 \%(n=18)$ of patients were normotensive. Significant number of RA patients were hypertensive $(\mathrm{p}<0.030)$.

Gender Distribution Of Hypertension
\begin{tabular}{|l|l|l|l|l|}
\hline HYPERTENSION & FREQUENCY & PERCENTAGE \\
\hline & & & Male & Female \\
\hline & Male & Female & & \\
\hline YES & 7 & 25 & 58 & 66 \\
\hline NO & 5 & 13 & 42 & 34 \\
\hline Total & 12 & 38 & 100 & 100 \\
\hline
\end{tabular}

In our study among 12 males, $58 \%(\mathrm{n}=7)$ of males were hypertensive and among 38 females, $66 \%$ $(\mathrm{n}=25)$ were hypertensive. More number of female patients $(\mathrm{p}<0.030)$ were hypertensive compared to male patients.

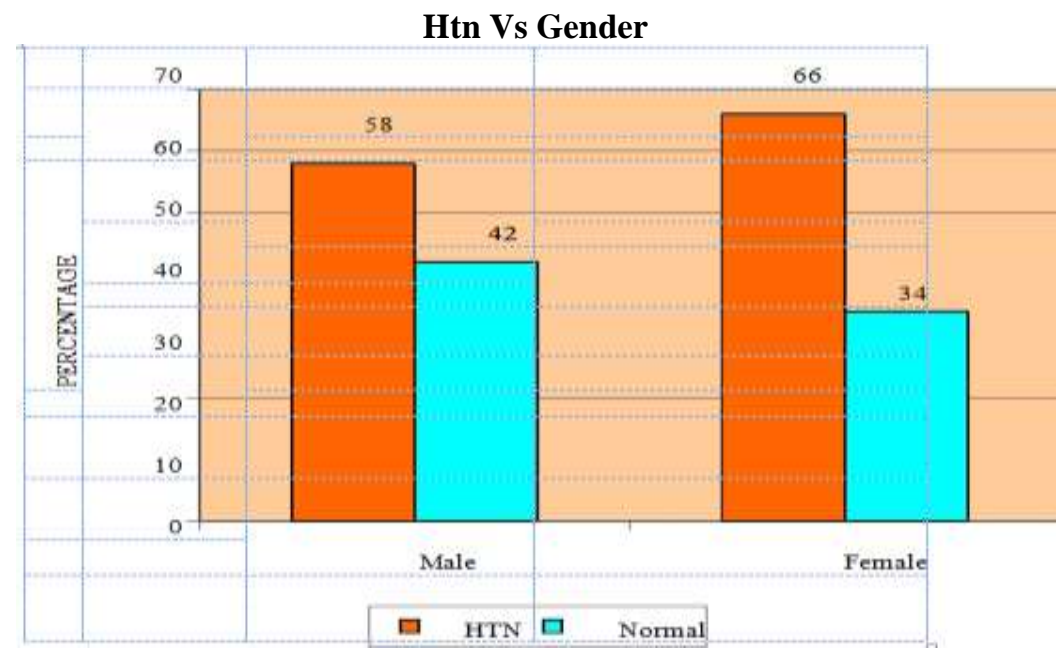

Age Distribution Of Hypertension In Ra

\begin{tabular}{|l|l|l|l|l|l|l|l|l|}
\hline HTN vs Age & \multicolumn{3}{|c|}{ FREQUENCY } & \multicolumn{3}{l|}{ PERCENTAGE } \\
\hline & $<35$ & & $35-45$ & & $>45$ & $<35$ & $35-45$ & $>45$ \\
\hline HTN & 2 & & 12 & & 18 & 25 & 67 & 75 \\
\hline Normal & 6 & & 6 & & 6 & 75 & 33 & 25 \\
\hline Total & 8 & & 18 & & 24 & 100 & 100 & 100 \\
\hline
\end{tabular}

In our study among 18 patients who were aged between 35-45 years, $67 \%(\mathrm{n}=12)$ were hypertensive $(\mathrm{p}<0.008)$ and among 24 patients who were aged $>45$ years, $75 \%(n=18)$ were hypertensive. Both were 
significant. Compared with patients $<35$ years, hypertension was more prevalent in patients aged $>45$ years $(\mathrm{p}<0.001)$. Prevalence of hypertension is increasing with age.

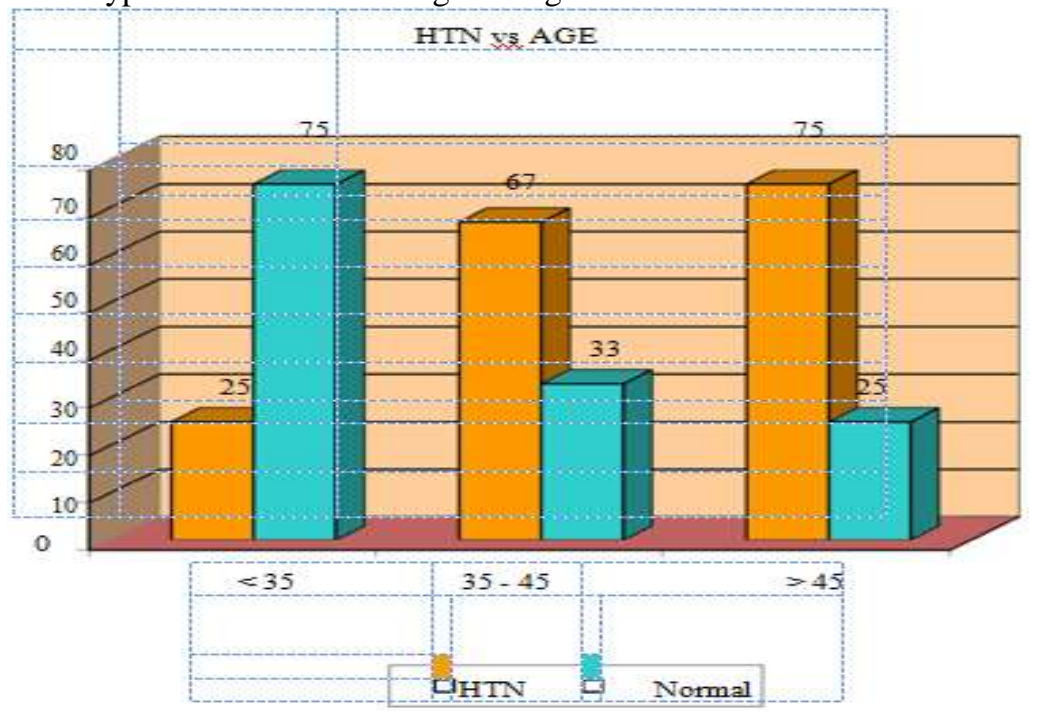

Impaired Glucose Metabolism (Pre-Diabetes And Diabetes) In Ra

\begin{tabular}{|l|l|l|}
\hline Glucose metabolism & FREQUCENCY & PERCENTAGE \\
\hline Normal & 17 & 34 \\
\hline Impaired & 33 & 66 \\
\hline Total & 50 & 100 \\
\hline
\end{tabular}

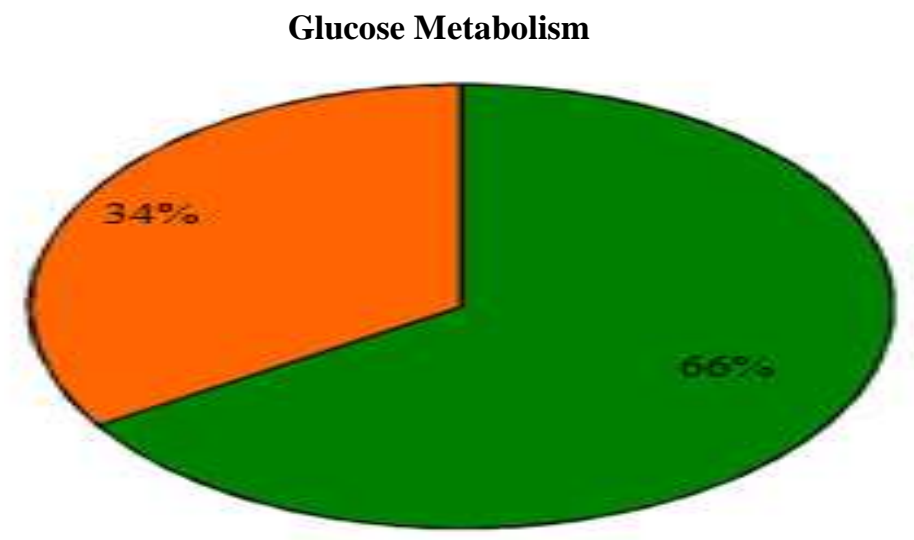

Glucose Metabolism

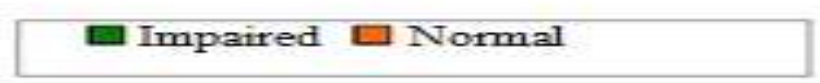

In our study $66 \%(n=33)$ of patients had impaired glucose metabolism and $34 \%(n=17)$ of patients had normal glucose metabolism. Impaired glucose metabolism is statistically significant $(\mathrm{p}<0.012)$.

Gender Distribution Of Impaired Glucose Metabolism In Ra

\begin{tabular}{|l|l|l|l|l|}
\hline IMPAIRED & & & \multicolumn{2}{l|}{} \\
\hline GLUCOSE & & & & \\
\hline METABOLISM VS & & & & \\
\hline GENDER & FREQUENCY & PERCENTAGE & \\
\hline & Male & Female & Male & Female \\
\hline Impaired & 8 & 25 & 67 & 66 \\
\hline Normal & 4 & 13 & 33 & 34 \\
\hline Total & 12 & 38 & 100 & 100 \\
\hline
\end{tabular}


In our study out of 12 males, $8(67 \%)$ had impaired glucose metabolism and out of 38 females, 25 $(66 \%)$ had impaired glucose metabolism. Both male $(\mathrm{p}<0.008)$ and female $(\mathrm{p}<0.012)$ patients had significant impaired glucose metabolism.

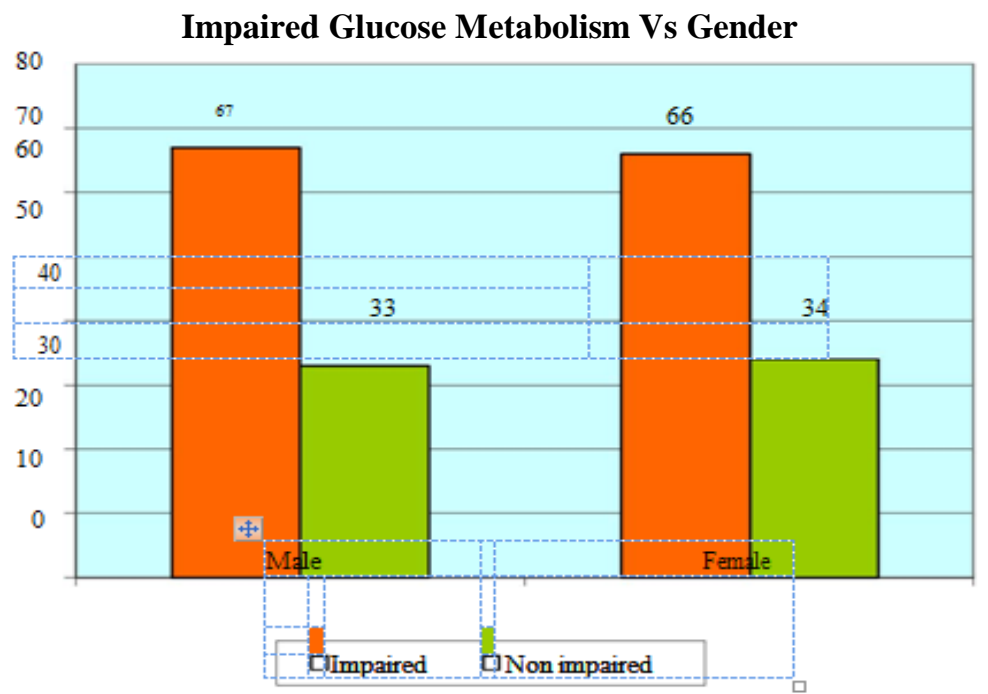

\begin{tabular}{|c|c|c|c|c|c|c|}
\hline \multicolumn{7}{|c|}{ Age Distribution Of Impaired Glucose Metabolism In Ra } \\
\hline IMPAIRED & & & & & & \\
\hline GLUCOSE & & & & & & \\
\hline METABOLISM & & & & \multicolumn{3}{|c|}{ PERCENTAGE } \\
\hline VS AGE & & \multicolumn{2}{|l|}{ FREQUENCY } & & & \\
\hline & $<35$ & $35-45$ & $>45$ & $<35$ & $35-45$ & $>45$ \\
\hline Impaired & 3 & 12 & 18 & 38 & 67 & 75 \\
\hline Normal & 5 & 6 & 6 & 62 & 33 & 25 \\
\hline Total & 8 & 18 & 24 & 100 & 100 & 100 \\
\hline
\end{tabular}

In our study out of 8 males aged < 35 years, 3 (38\%) had impaired glucose metabolism and out of 18 males aged 35-45 years, $12(67 \%)$ had significant impaired glucose metabolism $(\mathrm{p}<0.008)$. Out 24 patients (age $>45$ years), $18(75 \%)$ had impaired glucose metabolism which is statistically significant $(\mathrm{p}<0.001)$. Compared with patients aged <35 (38\%), patients with age $>45$ years had significant impaired glucose metabolism $(\mathrm{p}<0.008)$ which shows that prevalence of impaired glucose metabolism increasing with age.

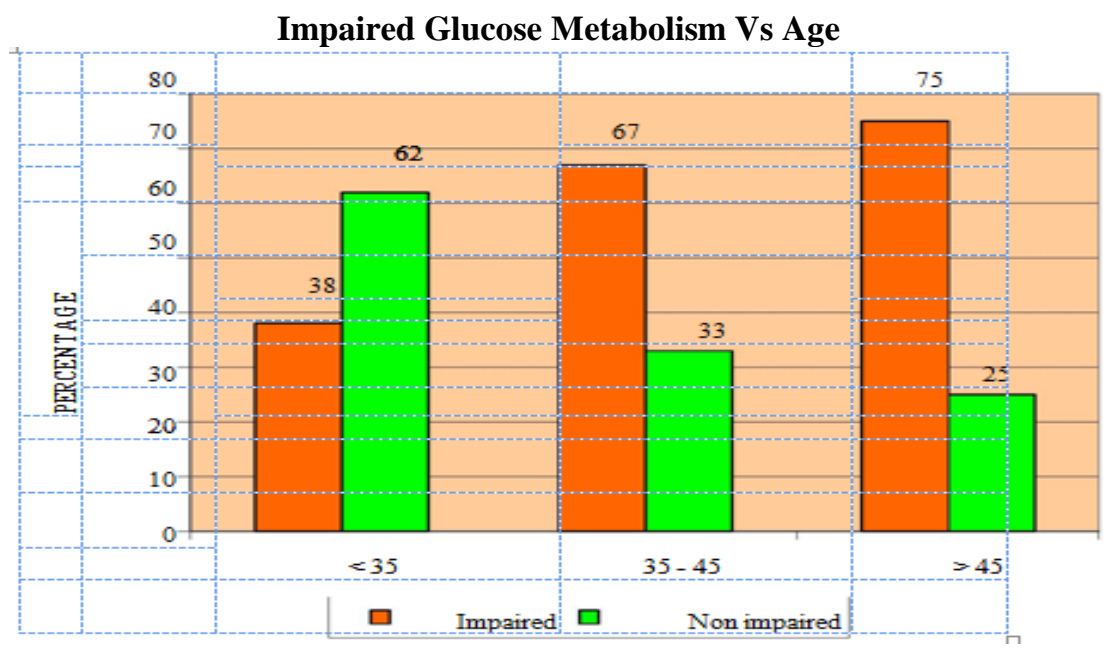

Frank Diabetes In Ra

\begin{tabular}{|l|l|l|}
\hline Diabetes & FREQUENCY & PERCENTAGE \\
\hline Yes & 11 & 22 \\
\hline No & 39 & 78 \\
\hline Total & 50 & 100 \\
\hline
\end{tabular}




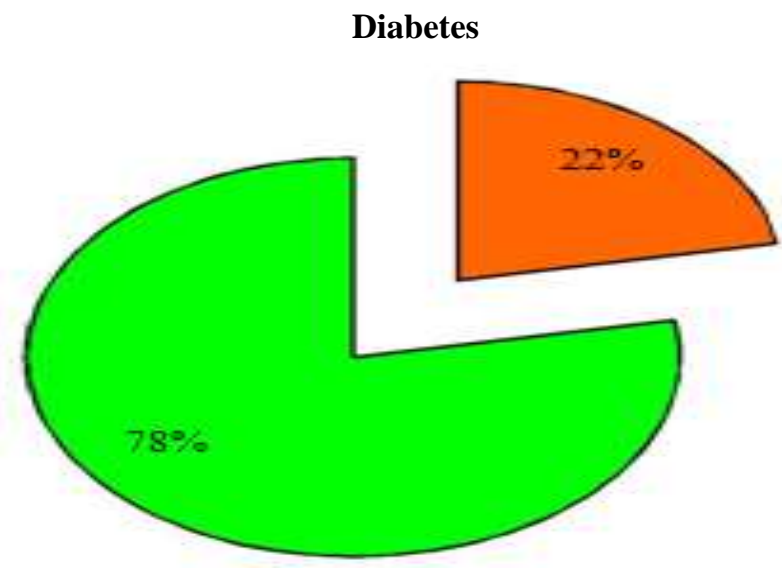

口Yes $\square$ No

In our study 11(22\%) had diabetes out of 50 patients. Among 66\% of patients with impaired glucose metabolism (pre-diabetes and diabetes), frank diabetes contributed $22 \%$. Statistically it is not significant.

\section{Gender Distribution Of Diabetes In Ra}

\begin{tabular}{|l|l|l|l|l|}
\hline DIABETES VS & \multicolumn{2}{|l|}{ PERCENTAGE } \\
\cline { 1 - 3 } & FREQUENCY & \multicolumn{3}{l|}{} \\
\cline { 1 - 3 } & Male & Female & Male & Female \\
\hline Diabetic & 2 & 9 & 16 & 24 \\
\hline Non Diabetic & 10 & 29 & 84 & 76 \\
\hline Total & 12 & 38 & 100 & 100 \\
\hline
\end{tabular}

In our study $2(16 \%)$ males had diabetes out of 12 and $12(24 \%)$ females had diabetes out of 38 . Prevalence of diabetes is higher in female RA patients.

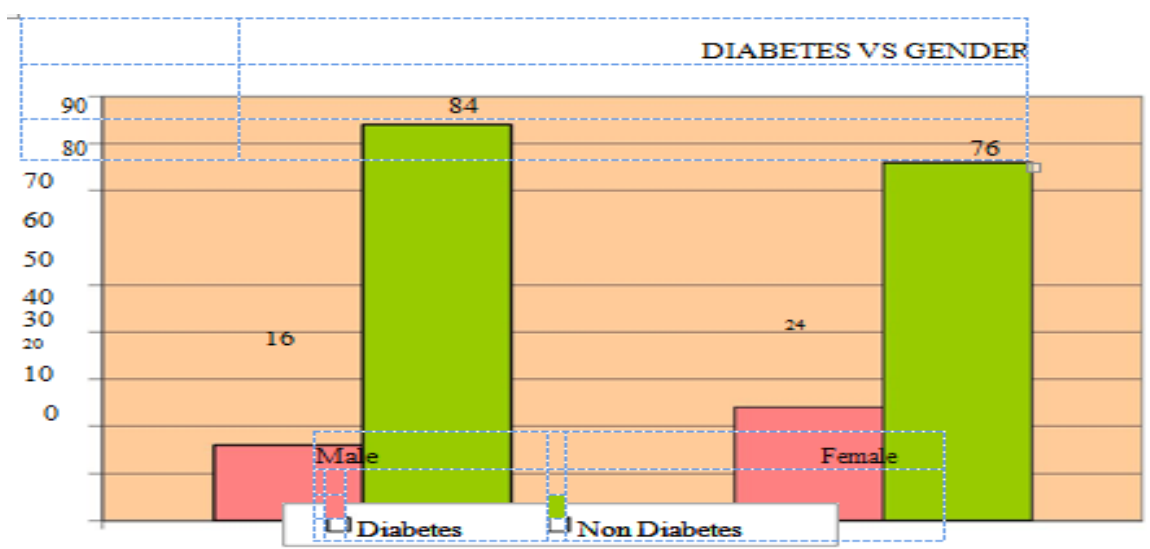

Age Distribution Of Diabetes In Ra

\begin{tabular}{|l|l|l|l|l|l|l|l|l|l|l|}
\hline DIABETES VS & & & & & & & & & \\
\hline AGE & & FREQUENCY & & & \multicolumn{2}{|l|}{ PERCENTAGE } & \\
\hline & $<35$ & & $35-45$ & & $>45$ & $<35$ & & $35-45$ & $>45$ \\
\hline Diabetic & 0 & & 3 & & 8 & 0 & & 17 & & 33 \\
\hline Non Diabetic & 8 & & 15 & & 16 & 100 & & 83 & \\
\hline Total & 8 & & 18 & & 24 & 100 & & 100 & \\
\hline
\end{tabular}


In our study $3(17 \%)$ out of 18 had diabetes in the age group of 35-45 years and $8(33 \%)$ out 24 had diabetes in the age group $>45$ years. Prevalence of diabetes is higher in the patients aged $>45$ years but it is not statistically significant.
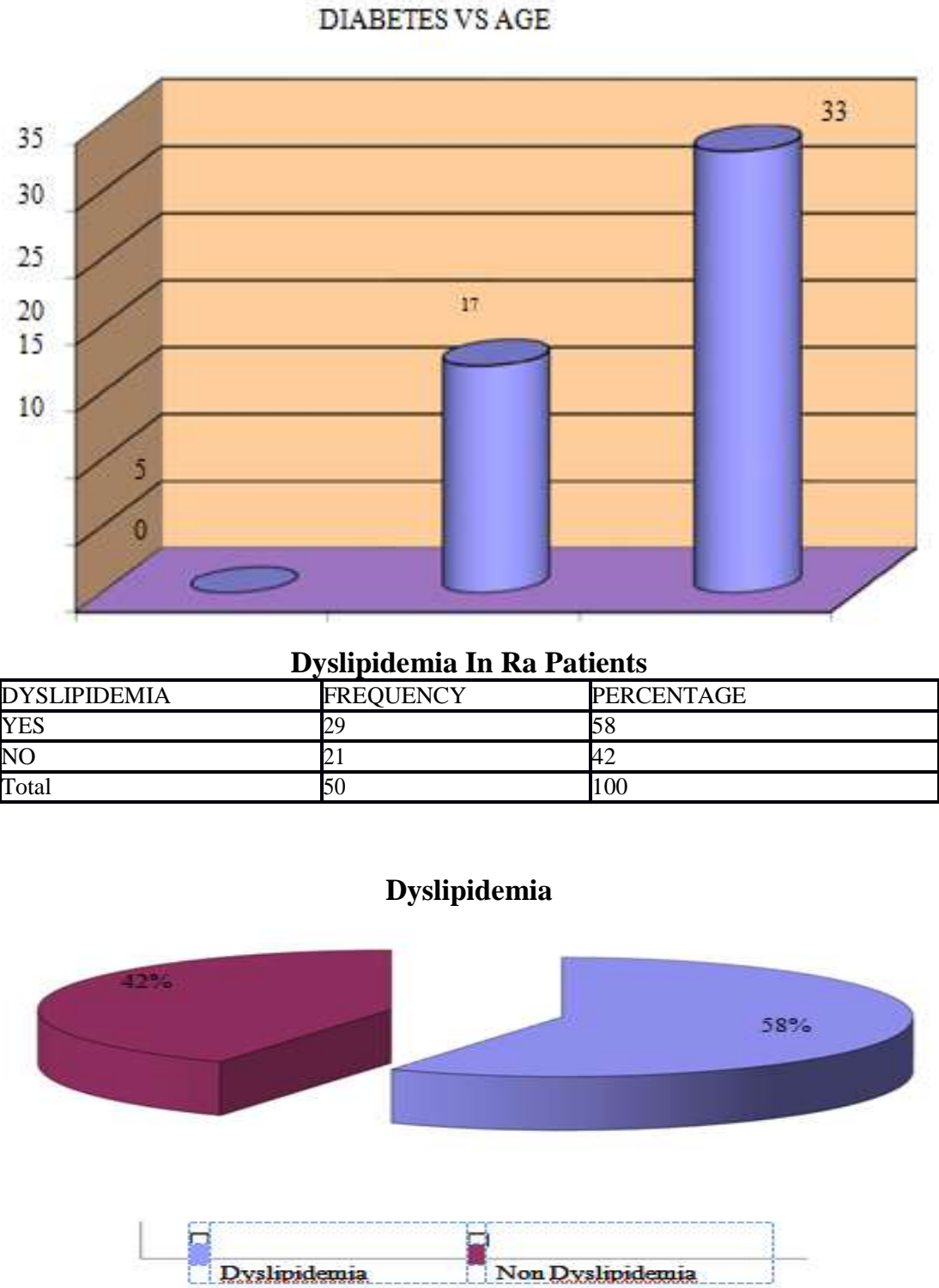

In our study $29(58 \%)$ out of 50 patients had dyslipidemia. Though significant number of patients had dyslipidemia $\mathrm{P}$ value is $<0.236$ (statistically not significant).

Gender distribution of dyslipidemia in ra patients.
\begin{tabular}{|l|l|l|l|l|}
\hline DYSLIPIDEMIA VS & \multicolumn{3}{l|}{} & \multicolumn{2}{l|}{} \\
\hline GENDER & FREQUENCY & PERCENTAGE & Female \\
\hline & Male & Female & Male & 66 \\
\hline Dyslipidemia & 4 & 25 & 33 & 34 \\
\hline Non Dyslipidemia & 8 & 13 & 67 & 100 \\
\hline Total & 12 & 38 & 100 & \\
\hline
\end{tabular}

In our study 4 (33\%) out of 12 male patients had dyslipidemia and $25(66 \%)$ out of 38 female patients had dyslipidemia. Compared with male, prevalence of dyslipidemia is higher in female patients $(p<0.012$ significant). 


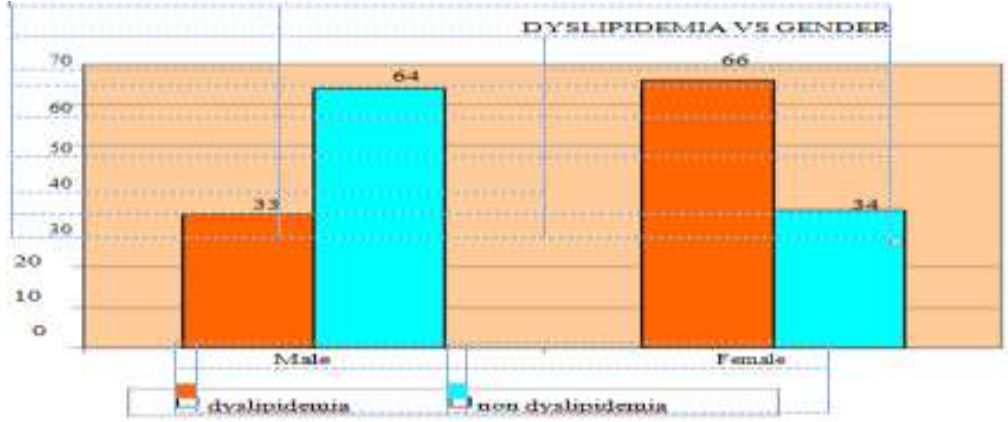

Age distribution of dyslipidemia in ra patients.

\begin{tabular}{|l|l|l|l|l|l|l|l|l|l|l|}
\hline DYSLIPIDEMIA & \multicolumn{2}{|c|}{} & & & & \multicolumn{2}{|c|}{} & \\
\hline VS AGE & & \multicolumn{2}{|c|}{ FREQUENCY } & & & \multicolumn{2}{|c|}{ PERCENTAGE } & \\
\hline & $<35$ & & $35-45$ & & $>45$ & $<35$ & & $35-45$ & & $>45$ \\
\hline Yes & 3 & & 10 & & 16 & 38 & & 56 & & 67 \\
\hline No & 5 & & 8 & & 8 & 62 & & 44 & & 33 \\
\hline Total & 8 & & 18 & & 24 & 100 & & 100 & & 100 \\
\hline
\end{tabular}

In our study 3 (38\%) out of 8 patients in the age group of <35 years had dyslipidemia and $10(56 \%)$ out of 18 patients in the age group of 35-45 years had dyslipidemia. In the age group of $>45$ years $16(67 \%)$ out of 24 patients had dyslipidemia. Prevalence of dyslipidemia is increasing with age with maximum incidence in patients $>45$ years $(\mathrm{p}<0.047$ significant $)$.

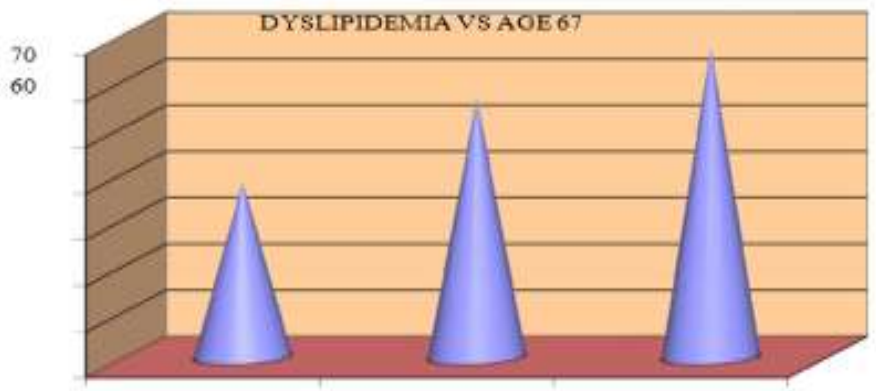

Metabolic Syndrome In Ra
\begin{tabular}{|l|l|l|}
\hline Metabolic syndrome & Frequency & Percentage \\
\hline Yes & 24 & 48 \\
\hline No & 26 & 52 \\
\hline Total & 50 & 100 \\
\hline
\end{tabular}

\section{Metabolic Syndrome}
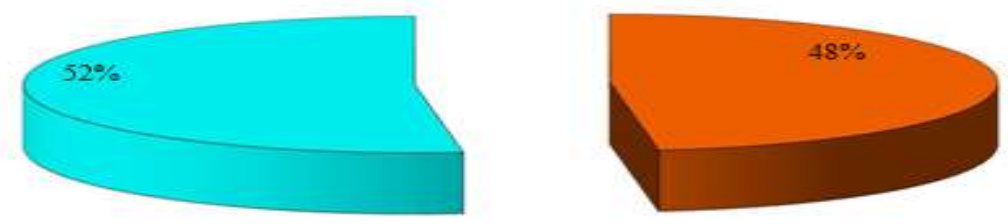

$\square$ Yes $\square$ No

In our study 24 (48\%) out of 50 patients had metabolic syndrome according to NCEP:ATP III 2001 but P value is $<0.838$ (not significant).

Gender Distribution Of Metabolic Syndrome
\begin{tabular}{|l|l|l|l|l|}
\hline METABOLIC & & & \\
\hline SYNDROME VS & & & & \\
\hline GENDER & FREQUENCY & PERCENTAGE \\
\hline
\end{tabular}


A Study Of The Association Of Impaired Glucose Metabolism In Patients With Newly....

\begin{tabular}{|l|l|l|l|l|}
\hline & Male & Female & Male & Female \\
\hline Yes & 4 & 20 & 33 & 53 \\
\hline No & 8 & 18 & 67 & 47 \\
\hline Total & 12 & 38 & 100 & 100 \\
\hline
\end{tabular}

In our study $4(33 \%)$ out of 12 male patients full filled the criteria for metabolic syndrome and in female patients $20(53 \%)$ out of 38 full filled the criteria for metabolic syndrome. Female patients had higher prevalence of metabolic syndrome but it is not significant statistically.

\section{Metabolic Syndrome Vs Gender}

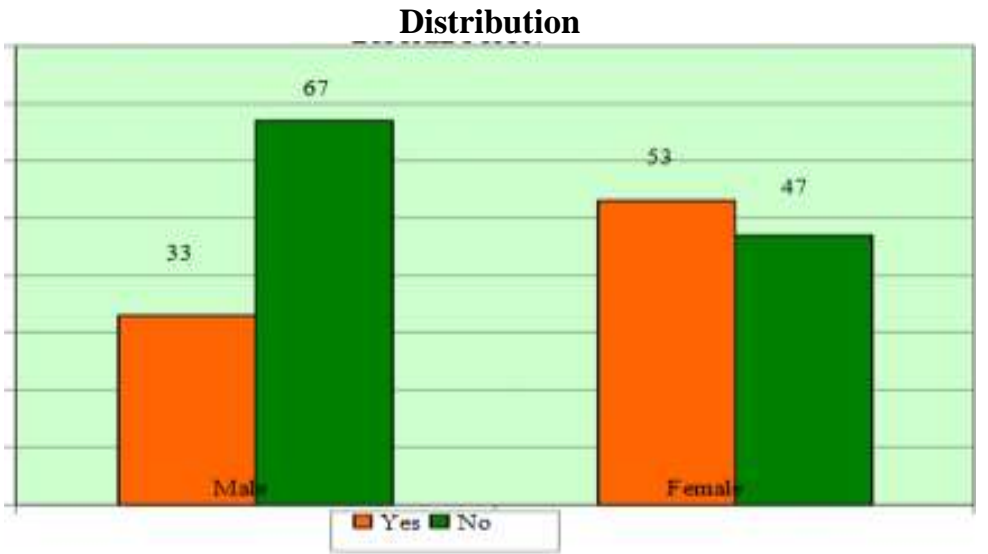

Age Distribution Of Metabolic Syndrome In Ra

\begin{tabular}{|l|l|l|l|l|l|l|l|l|l|}
\hline METABOLIC & & & & & & & & \\
\hline SYNDROME & & \multicolumn{2}{|l|}{} & & & & & & \\
\hline VS AGE & & \multicolumn{2}{|c|}{ FREQUENCY } & & & & \multicolumn{2}{l|}{ PERCENTAGE } \\
\hline & $<35$ & & $35-45$ & & $>45$ & $<35$ & & $35-45$ & $>45$ \\
\hline Yes & 2 & & 7 & & 15 & 25 & & 39 & 63 \\
\hline No & 6 & & 11 & & 9 & 75 & & 61 & 37 \\
\hline Total & 8 & & 18 & 24 & 100 & & 100 & 100 \\
\hline
\end{tabular}

In our study $7(39 \%)$ out of 18 patients full filled the criteria for metabolic syndrome in the age group of 35-45 years and 15 (63\%) out of 24 patients full filled the criteria for metabolic syndrome in the age group of $>45$ years $(\mathrm{p}<0.045$ significant). Increasing age is found to be risk factor for metabolic syndrome.

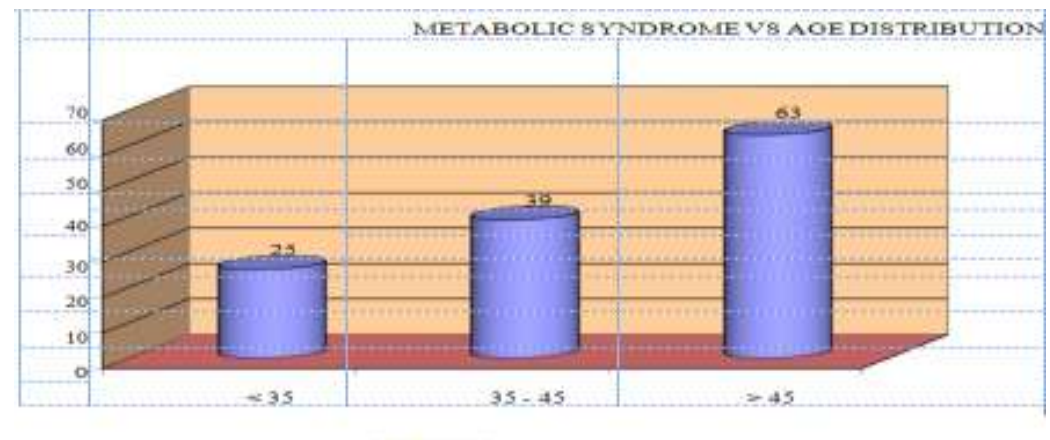

$\square$ rom

Rf Positive Vs Negative

\begin{tabular}{|l|l|l|l|l|l|l|}
\hline & Obese & HTN & IGM & Dyslipidemia & Metab.syn & TOTAL \\
\hline RF & & & 31 & & & \\
\hline Positive & $32(73 \%)$ & $30(68 \%)$ & $(71 \%)$ & $28(64 \%)$ & $23(52 \%)$ & 44 \\
\hline RF & & & & & & \\
\hline Negative & $2(32 \%)$ & $2(32 \%)$ & $2(32 \%)$ & $1(16 \%)$ & $1(16 \%)$ & 6 \\
\hline
\end{tabular}

In our study $73 \%$ of RF positive patients had obesity and $32 \%$ of RF negative patients had obesity $(\mathrm{P}<0.002$ significant). $68 \%$ of $\mathrm{RF}$ positive patients were hypertensive $(\mathrm{P}<0.005$ significant $)$ and $32 \%$ of $\mathrm{RF}$ negative patients were hypertensive. $71 \%$ of RF positive patients had impaired glucose metabolism $(\mathrm{P}<0.002$ significant) and $32 \%$ of RF negative patients had impaired glucose metabolism. Dyslipidemia was seen $64 \%$ of RF positive $(\mathrm{P}<0.001$ significant) and $16 \%$ of RF negative patients. Criteria for metabolic syndrome was full 
filled by $52 \%$ of RF positive $(\mathrm{P}<0.001)$ and $16 \%$ RF negative patients. Patients with RF positive had higher prevalence of obesity, hypertension, impaired glucose metabolism, dyslipidemia and metabolic syndrome and carries poor prognosis.

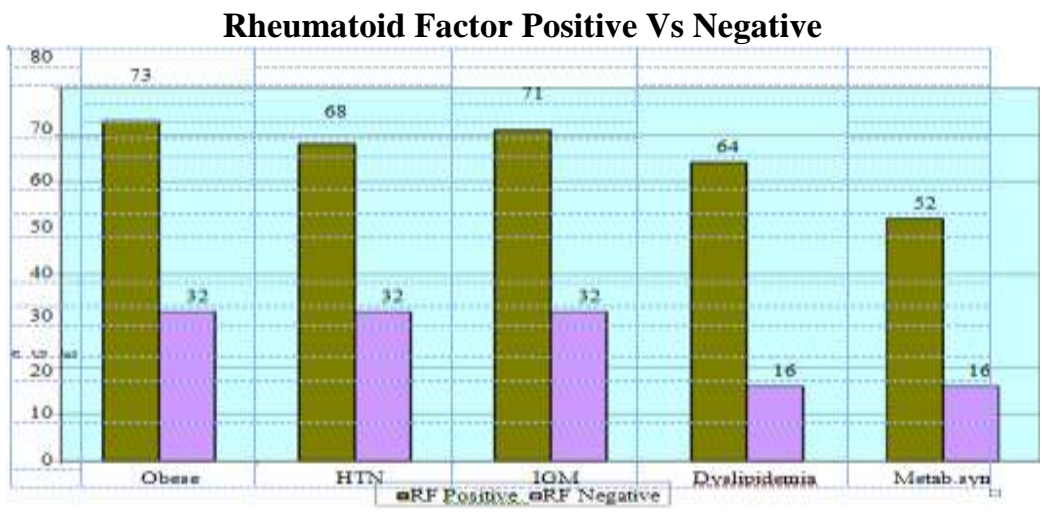

Duration Of Symptoms In Ra

\begin{tabular}{|l|l|l|l|l|}
\hline \multicolumn{2}{|l|}{ Duration of Symptoms } & Frequency & Percentage \\
\hline$<$ & 6 months & 14 & 28 \\
\hline $6-$ & 1 & 2 months & 25 & 50 \\
\hline$>12$ & months & 11 & 22 \\
\hline & 50 & 100 \\
\hline
\end{tabular}

\section{Duration Of Symptoms}

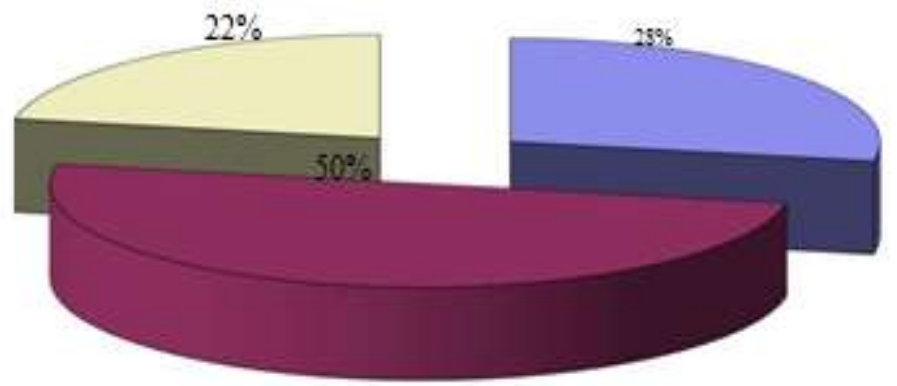

< 6 months $\square 6-12$ months $\square>12$ months

In our study group $28 \%(\mathrm{n}=14)$ of patients had duration of symptoms $<6$ months and $50 \%(\mathrm{n}=25)$ of patients had duration of symptoms 6-12 months. $22 \%(\mathrm{n}=11)$ of patients were symptomatic $>12$ months. Majority of patients were symptomatic for 6 to 12 months.

Distribution Of Duration Symprtoms

\begin{tabular}{|c|c|c|c|c|c|c|c|c|}
\hline \multicolumn{9}{|l|}{ Duration } \\
\hline \multicolumn{9}{|l|}{ of } \\
\hline Symptoms & Obese & HTN & & IGM & \multicolumn{2}{|c|}{ Dyslipidemia } & Metab.syn & Total \\
\hline$<6$ month & $9(64 \%)$ & $8(57 \%)$ & 8 & $(57 \%)$ & 5 & $(36 \%)$ & $4(29 \%)$ & 14 \\
\hline $6-12$ & 17 & 16 & & & & & & \\
\hline month & $(68 \%)$ & $(64 \%)$ & \multicolumn{2}{|c|}{$17(68 \%)$} & \multicolumn{2}{|c|}{$16(64 \%)$} & $13(52 \%)$ & 25 \\
\hline \multicolumn{9}{|l|}{$>12$} \\
\hline \multirow[t]{2}{*}{ month } & $8(73 \%)$ & $8(73 \%)$ & 8 & $(73 \%)$ & 8 & $(73 \%)$ & $7(64 \%)$ & 11 \\
\hline & 34 & 32 & & & & & 20 & \\
\hline Total & $(100 \%)$ & $(100 \%)$ & 24 & $(100 \%)$ & 22 & $(100 \%)$ & $(100 \%)$ & 50 \\
\hline
\end{tabular}

In our study patients who were symptomatic for less than 6 months had prevalence of obesity- $64 \%$ ( $\mathrm{P}<0.045$ significant), hypertension-57\%, impaired glucose metabolism-57\%, dyslipidemia-36\% and metabolic syndrome-29\%. Patients with symptoms 6-12 month had prevalence of obesity-68\% ( $\mathrm{P}<0.008$ significant), 
hypertension-64\% ( $\mathrm{p}<0.045)$, impaired glucose metabolism-68\% $(\mathrm{P}<0.008)$, dyslipidemia-64\% $(\mathrm{P}<0.045)$ and metabolic syndrome-52\%. Patients with symptoms $>12$ months had prevalence of statistically significant obesity-73\% ( $\mathrm{p}<0.002$ significant), hypertension-73\% ( $<<0.002)$, impaired glucose metabolism-73\% $(\mathrm{p}<0.002)$, dyslipidemia-73\% $(\mathrm{P}<0.002)$ and metabolic syndrome-64\% $(\mathrm{P}<0.045$ significant $)$. Patient with long standing symptoms have more co-morbid illness.

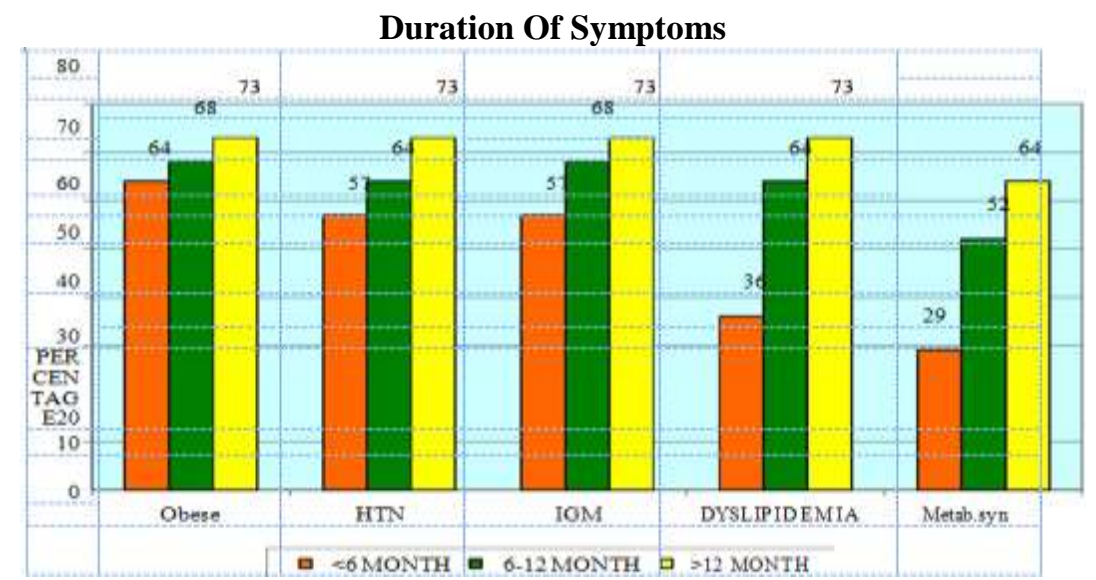

Small Joint Involvemant In Ra

\begin{tabular}{|l|l|l|}
\hline SMALL JOINT & & \\
\hline INVOLVEMENT & FREQUENCY & Percentage \\
\hline $1-3$ & 6 & 12 \\
\hline $4-10$ & 31 & 62 \\
\hline$>10$ & 13 & 26 \\
\hline Total & 50 & 100 \\
\hline
\end{tabular}

Joint Involvement
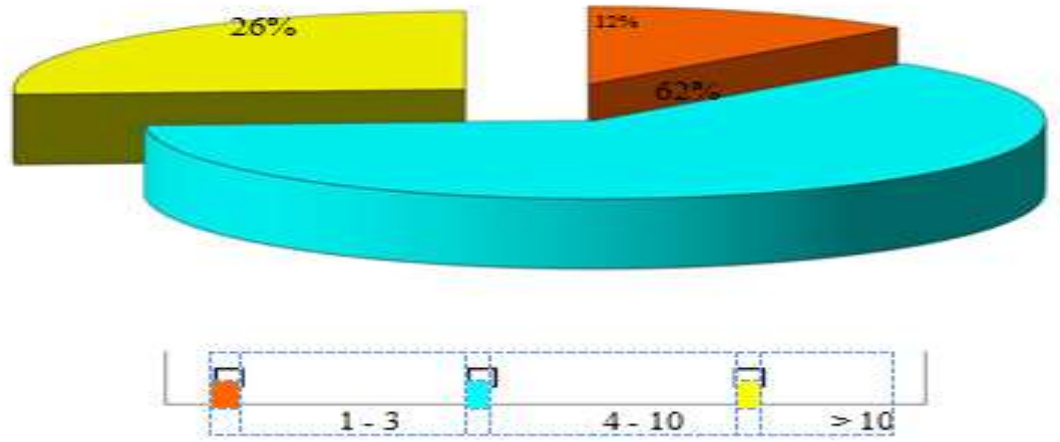

In our study $26 \%(n=13)$ patients had involvement of $1-3$ small joints, $62 \%(n=31)$ of patients had 410 and $12 \%(n=6)$ have $>10$ small joint involvement.

Joint Involvement Vs Co-Morbid Illness

\begin{tabular}{|l|l|l|l|l|l|l|l|l|}
\hline JOINT & & & & & & & \\
\hline INVOLVEMENT & Obese & HTN & IGM & \multicolumn{2}{|c|}{ Dyslipidemia } & \multicolumn{2}{|c|}{ Metab.syn } & Total \\
\hline & & 2 & 3 & & & & & \\
\hline $1-3$ & $3(50 \%)$ & $(33 \%)$ & $(50 \%)$ & 2 & $(33 \%)$ & 1 & $(17 \%)$ & 6 \\
\hline & 21 & 20 & 20 & & & & & \\
\hline $4-10$ & $(68 \%)$ & $(65 \%)$ & $(65 \%)$ & $18(58 \%)$ & $14(45 \%)$ & 31 \\
\hline$>10$ & 10 & 10 & 10 & & & & & \\
\hline & $(77 \%)$ & $(77 \%)$ & $(77 \%)$ & 9 & $(69 \%)$ & 9 & $(69 \%)$ & 13 \\
\hline Total & 34 & 32 & 33 & & & & & \\
\hline
\end{tabular}

In our study out of 6 patients with involvement of 1-3 small joint involvement, obesity and impaired glucose metabolism were seen in 3 patients. 2 patients had hypertension and dyslipidemia. Metabolic syndrome was seen in one patients. 
In patients with involvement of 4-10 small joint out $(n=31), 65 \%$ of patients had impaired glucose metabolism and hypertensive ( $\mathrm{p}<0.023$ significant). Obesity was seen $68 \%$ of patients $(\mathrm{p}<0.008$ significant). Dyslipidemia and metabolic syndrome was seen $58 \%, 45 \%$ of patients respectively.

Out of 13 patients with involvement of $>10$ small joint, $77 \%$ of patients had hypertension, impaired glucose metabolism and obesity $(\mathrm{p}<0.001$ significant). $69 \%$ of patients have dyslipidemia and metabolic syndrome ( $\mathrm{p}<0.08$ significant).

So patients with more number of joint involvement and increasing disease activity are prone to impaired glucose metabolism, hypertension and metabolic syndrome. Hence it is important to treat the disease in early stage.

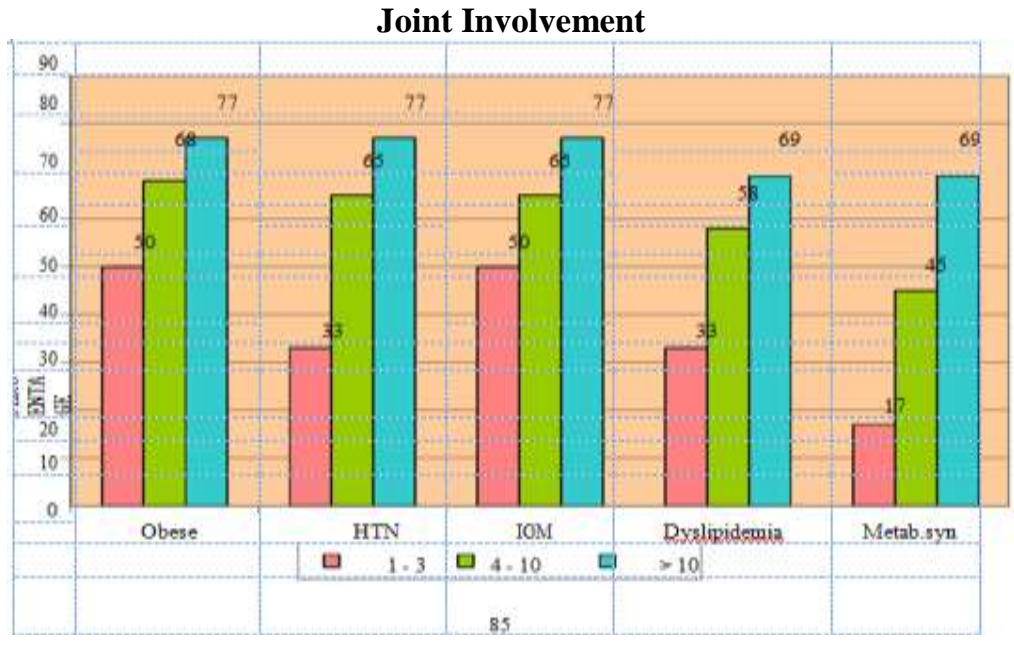

\section{IV. Discussion}

The study was conducted in the patients who attended Rheumatologic clinic, Govt Rajaji hospital, Madurai. Diagnosis of Rheumatoid arthritis was made according to ACR-EULAR 2010 criteria. Only new diagnosed treatment naïve patients were included in this study. After applying exclusion criteria 50 patients were selected for study.

Out of 50 patients 38 patients were female and 12 patients were male (3:1). It is consistent with previous studies because autoimmune nature of disease RA is more common female.

Rheumatoid factor was positive in 44 patients and negative in 6 patients. Sensitivity of Rheumatoid factor was $88 \%(\mathrm{p}<0.001$ significant). Negative test for Rheumatoid factor doesn't rule out diagnosis of Rheumatoid arthritis because diagnostic sensitivity of RF is around $80 \%$ only.

Out of 50 patients 8 patients were $<35$ years, 18 patients $35-45$ years and 24 patients $>45$ years. Mean age of patient in this study was 42.06 years. With increasing age prevalence of RA was increasing.

As like previous studies conducted by Roubenoff and colleagues, central obesity was seen in $68 \%$ of patients which statistically significant $(\mathrm{p}<0.005$ significant). In our study women were more prone for central obesity (Rheumatoid cachexia). It is consistent with previous studies like conducted by Giles et al., . Prevalence of obesity was increasing with increasing age, long duration of symptoms, more number of joint involvement and high degree of inflammation. Because central obesity one of the key factor responsible for insulin resistance early diagnosis of RA and introduction of treatment is important to control inflammation. Controlling of inflammation improves obesity.

In our study $66 \%$ of patients had impaired glucose metabolism which was statistically significant ( $\mathrm{p}<0.012$ ). Out of $66 \%$ of patients with impaired glucose metabolism (pre-diabetes and diabetes), $22 \%$ of patients had frank diabetes. As we knew from previous studies like conducted by Patrick H. Dessein et al., age, high grade inflammation and long duration of disease are important risk factor for impaired glucose metabolism. In our study also impaired glucose metabolism was more prevalent with increasing age ( $>45$ years $75 \%$ ), long duration of disease (>12 months 73\%) and high grade of inflammation (>10 small joint involvement $77 \%$ ) which is consistent with previous studies. By controlling inflammation with early diagnosis and introduction of treatment we can improve impaired glucose metabolism.

In our study hypertension was seen $64 \%$ of patients $(\mathrm{p}<0.030$ significant $)$ which is consistent with previous studies like conducted by Dessein et al., . In previous studies like conducted by chung et al., reported presence of metabolic syndrome in 
$42 \%$ patients with long standing disease. In our study also dyslipidemia and metabolic syndrome was seen in 58 $\%$ and $48 \%$ of patients respectively which is consistent with previous studies.. All these risk factors for cardiovascular disease was seen in patients with long standing disease and high grade inflammation.

In our study compared with Rheumatoid factor negative patients, patients with Rheumatoid factor positive were more prone to impaired glucose metabolism, hypertension and metabolic syndrome. Hence patients with Rheumatoid factor positive were more prone to cardiovascular disease.

\section{Limitation}

- $\quad$ Sample size is small.

- The study population involved patients seeking medical care in our hospital which is a tertiary care center and hence they may not represent the general population.

\section{Conclusion}

In our study obesity, impaired glucose metabolism, hypertension, dyslipidemia and metabolic syndrome were seen in $68 \%, 66 \%, 64 \%, 58 \%$ and $48 \%$ of patients respectively.

- Long duration of disease and disease activity is important risk of factor impaired glucose metabolism, obesity, dyslipidemia, hypertension and metabolic syndrome.

- Impaired glucose metabolism and metabolic syndrome carries high risk of cardiovascular disease.

- Early diagnosis and early introduction of treatment will reduce disease activity and control inflammation.

- By controlling inflammation we can reduce risk of impaired glucose metabolism and metabolic syndrome.

- We can improve long term survival of Rheumatoid arthritis patients.

\section{Summary}

This prospective observational study was conducted to identify the prevalence of impaired glucose metabolism and other to cardiovascular risk factors in Rheumatoid arthritis patients.

With 50 patients were selected carefully and were evaluated on clinical and laboratory aspects after institutional ethical clearance with an informed consent. The data were entered in Microsoft Excel spread sheet and analysed statistically.

Prevalence of central obesity, impaired glucose metabolism, hypertension, dyslipidemia and metabolic syndrome is seen $68 \%, 66 \%, 64 \%, 58 \%$ and $48 \%$ of newly detected treatment naive Rheumatoid arthritis patients.

Age, disease activity and duration of disease is found to be important key factor in induction of impaired glucose metabolism and other cardiovascular risk factors.

In our study many of the patients are diagnosed after one year of symptoms. Hence early diagnosis is important to prevent this cardiovascular risk factors. Because disease activity correlate with cardiovascular risk factors early control of disease activity is important. atient with obesity shows poor response to Anti- TNF agents. So measures to reduce to obesity like exercise should be considered along with DMARDs.

So with early diagnosis and early introduction of treatment we can reduce the prevalence of impaired glucose metabolism, hypertension, obesity, dyslipidemia and metabolic syndrome in Rheumatoid arthritis patient. With all these measures we can reduce the risk of cardiovascular disease and improve long term survival of Rheumatoid arthritis patients.

\section{Acknowledgement}

I would like to thank The Dean Dr.Revwathy Kailairajan, Madurai Medical College, for permitting me to use the hospital facilities for the dissertation. I also extend my sincere thanks to Dr.V.T.PREMKUMAR M.D, Head of the Department and Professor of Medicine for his constant support during the study.

I would like to express my deep sense of gratitude and thanks to my unit Chief, Dr. C. dharmaraj m.d. dch, my guide and Professor of Medicine, for his valuable suggestions and excellent guidance during the study.I also sincerely thank our beloved professors DR.R.Balajinathan M.D, Dr.M.Natarajan M.D, Dr.C.Bagialakshmi M.D, Dr.J.Sangumani M.D, Dr.R.Prabhakaran M.D for their par excellence clinical teaching and constant support.

I thank the Assistant Professors of my unit dr. M. Rajkumar m.d, dr. S. Senthur raja pandian m.d dm, for their help and constructive criticisms.

I offer my special thanks to Head of the department of MICROBIOLOGY and Head of the department of Bio Chemistry for their kind co-operation and valuable guidance.

I thank all the patients who participated in this study for their extreme patience and kind co-operation. 
I wish to acknowledge all those, including my Post graduate colleagues, my parents who have directly or indirectly helped me to complete this work with great success.

Above all I thank the Lord Almighty for his kindness and benevolence

\section{Bibliography}

[1]. Roubenoff R, Cannon JG, Kehayias JJ, Zhuang H, Dawson-Hughes B, et al., Rheumatoid cachexia: cytokine-driven hypermetabolism accompanying reduced body cell mass in chronic inflammation. J Clin Invest 1994;93:2379-86.

[2]. Giles JT, Ling SM, Ferrucci L, Bartlett SJ, Andersen RE, Towns M, et al. Abnormal body composition phenotypes in older rheumatoid arthritis patients: association with disease characteristics and pharmacotherapies. Arthritis Rheum 2008;59:807-15.

[3]. Catalan V, Gomez-Ambrosi J, Rodriguez A, Salvador J, Fruhbeck G. Adipokines in the treatment of diabetes mellitus and obesity. Expert Opin Pharmacother 2009;10:239-54.

[4]. Hotamisligil GS, Murray DL, Choy LN, Spiegelman BM. Tumor necrosis factor inhibits signaling from the insulin receptor. Proc Natl Acad Sci U S A 1994;91:4854-8.

[5]. G.S.Hotamisligil,P.Peraldi,A.Budavari,R.Ellis,M.F.White, and B. M. Spiegelman, "IRS-1-mediated inhibition of insulin receptortyrosinekinaseactivityinTNF- -andobesity-induced insulinresistance,'Science,vol.271,no.5249,pp.665-668,1996.

[6]. Bruun JM, Lihn AS, Verdich C, Pedersen SB, Toubro S, Astrup A, et al. Regulation of adiponectin by adipose tissuederived cytokines: in vivo and in vitro investigations in humans. Am J Physiol Endocrinol Metab 2003;285:E527-33.

[7]. Bokarewa M, Nagaev I, Dahlberg L, Smith U, Tarkowski A. Resistin, an adipokine with potent proinflammatory properties. J Immunol 2005;174:5789-95.

[8]. Oncul O, Top C, Ozkan S, Cavuslu S, Danaci M. Serum interleukin2levelsinpatientswithrheumatoidarthritisand correlation with insulin sensitivity. J Int Med Res 2002;30: 386-90.

[9]. J. Beltowski, "Leptin and atherosclerosis," Atherosclerosis, vol. 189,no.1,pp.47-60,2006.

[10]. N. Ouchi, S. Kihara, Y. Arita et al., "Novel modulator for endothelialadhesionmolecules:adipocyte-derivedplasmaprotein adiponectin," Circulation, vol. 100, no. 25, pp. 2473-2476, 1999.

[11]. Filkova M, Haluzik M, Gay S, Senolt L. The role of resistin as a regulator of inflammation: implications for various human pathologies. Clin Immunol 2009;133:157-70.

[12]. Firestein GS. Evolving concepts of rheumatoid arthritis. Nature 2003;423:356-61.

[13]. A. Fukuhara, M. Matsuda, M. Nishizawa et al., "Visfatin: a protein secreted by visceral fat that Mimics the effects of insulin,"Science,vol.307,no.5708,pp.426-430,2005.

[14]. J.F.Baker,N.N.Mehta,D.G.Bakeretal.,"VitaminD,metabolic dyslipidemia,andmetabolicsyndromeinrheumatoidarthritis," American Journal of Medicine, vol. 125, no. 10, pp. 1035.e09-1036.e15,2012.

[15]. Karin L.G. Svenson, Thomas Pollare, Hans Lithell, Roger Hallgren et al., Impaired glucose handling in active rheumatoid arthritis: Relationship to peripheral insulin resistance. Metabolism - clinical and Experimental volume 37, issue 2, February 1988.

[16]. Karin L. G. Svenson, Roger Hallgren et al., Impaired glucose handling in active rheumatoid arthritis: Relationship to the secretion of insulin and counter-regulatory hormones. Metabolism Volume 36, Issue 10, October 1987.

[17]. Svenson KL, Lundqvist G, Wide L, Hallgren R et al., Impaired glucose handling in active rheumatoid arthritis: effects of corticosteroids and antirheumatic treatment. Metabolism. 1987 Oct;36(10):944-8.

[18]. Patrick H. Dessein and Barry I. Joffe: Insulin resistance and impaired beta cell function in Rheumatoid arthritis. Arthritis \& Rheumatism Vol. 54, No. 9, September 2006.

[19]. Stumvoll M, Goldstein BJ, van Haeften TW. Type 2 diabetes: principles of pathogenesis and therapy. Lancet 2005;365:1333-46.

[20]. Sharma AM, Janke J, Gorenzelniak K, Engeli S, Luft FC. Angiotension blockade prevents type 2 diabetes by formation of fat cells. Hypertension 2002;40:609-11.

[21]. V. R. Da Cunha, C. V. Brenol, J. C. T. Brenol et al., "Metabolic syndrome prevalence is increased in rheumatoid arthritis patients and is associated with disease activity,"Scandinavian JournalofRheumatology,vol.41,no.3,pp.186- 191,2012.

[22]. C. S. Crowson, E. Myasoedova, J. M. Davis et al., "Increased prevalenceofmetabolicsyndromeassociatedwithrheumatoid arthritis in patients without clinical cardiovascular disease,” JournalofRheumatology,vol.38,no.1,pp.29-35,2011.

[23]. T. E. Toms, V. F. Panoulas, H. John, K. M. Douglas, and G. D. Kitas, "Methotrexate therapy associates with reduced prevalence of the metabolic syndrome in rheumatoid arthritis patientsovertheageof60-morethanjustananti-inflammatory effect? A cross sectional study," Arthritis Research \& Therapy, vol.11,no.4,p.R110,2009.

[24]. C. P. Chung, A. Oeser, J. F. Solus et al., "Prevalence of the metabolic syndrome is increased in rheumatoid arthritis and isassociatedwithcoronaryatherosclerosis,"Atherosclerosis,vol.

[25]. 196,no.2,pp.756-763,2008

[26]. L. S. Tam, B. Tomlinson, T. T. Chu, T. K. Li, and E. K. Li, "ImpactofTNFinhibitiononinsulinresistanceandlipidslevels in patients with rheumatoid arthritis," Clinical Rheumatology,vol.26,no.9,pp.1495-1498,2007.

[27]. B. Seriolo, S. Paolino, C. Ferrone, and M. Cutolo, "Impact of long-term anti-TNF- treatment on insulin resistance in patients with rheumatoid arthritis," Clinical and Experimental Rheumatology,vol.26,no.1,p.159,2008.

[28]. Gonzalez-Gay MA, De Matias JM, Gonzalez-Juanatey C, Garcia-Porrua C, Sanchez-Andrade A, Martin J, et al. Antitumor necrosis factor blockade improves insulin resistance in patients with rheumatoid arthritis. Clin Exp Rheumatol 2006;24:83-6.

[29]. 28. Carin Popa, Mihai G. Netea, Piet L. C. M. van Riel et al., The role of TNF- $\alpha$ in chronic inflammatory conditions, intermediary metabolism, and cardiovascular risk. Journal of Lipid research volume 48, 2007.

\section{Contents}

\begin{tabular}{|l|l|l|}
\hline S.NO & CONTENTS & PAGE \\
\hline 1. & INTRODUCTION & 1 \\
\hline 2. & AIM OF STUDY & 4 \\
\hline 3. & REVIEW OF LITERATURE & 5 \\
\hline 4. & MATERIALS AND METHODS & 32 \\
\hline 5. & RESULTS AND INTERPRETATION & 44 \\
\hline 6. & DISCUSSION & 78 \\
\hline 7. & CONCLUSION & 81 \\
\hline 8. & SUMMARY & 82 \\
\hline
\end{tabular}


A Study Of The Association Of Impaired Glucose Metabolism In Patients With Newly....

\begin{tabular}{|l|l|l|}
\hline 9. & ANNEXURES & 84 \\
\hline & BIBLIOGRAPHY & \\
\hline & PROFORMA & \\
\hline & MASTER CHART & \\
\hline & ETHICAL COMMITTEE APPROVAL LETTER & \\
\hline & ANTI PLAGIARISM CERTIFICATE & \\
\hline
\end{tabular}

\begin{tabular}{|c|c|c|c|c|c|c|c|c|c|c|}
\hline \multicolumn{11}{|c|}{ Master Chart } \\
\hline S.No & Sex & Age & $\mathrm{Rf}$ & S.Joint & Duration & Obesity & Igm & $\mathrm{Htn}$ & Dyslipidemia & Ms \\
\hline 1 & Female & 48 & Negative & 8 & 14 & Yes & Yes & Yes & No & Yes \\
\hline 2 & Female & 48 & Negative & 8 & 15 & Yes & No & Yes & No & No \\
\hline 3 & Female & 47 & Negative & 7 & 5 & No & Yes & No & No & No \\
\hline 4 & Female & 47 & Negative & 8 & 16 & No & No & No & Yes & No \\
\hline 5 & Male & 39 & Negative & 14 & 10 & No & No & No & No & No \\
\hline 6 & Male & 48 & Negative & 12 & 10 & No & No & No & No & No \\
\hline 7 & Male & 37 & Positive & 14 & 5 & Yes & Yes & Yes & Yes & Yes \\
\hline 8 & Male & 38 & Positive & 15 & 14 & Yes & Yes & Yes & Yes & Yes \\
\hline 9 & Male & 49 & Positive & 8 & 14 & Yes & Diabetic & Yes & Yes & Yes \\
\hline 10 & Male & 49 & Positive & 12 & 8 & Yes & Diabetic & Yes & Yes & Yes \\
\hline 11 & Male & 48 & Positive & 2 & 8 & Yes & Yes & No & No & No \\
\hline 12 & Male & 47 & Positive & 8 & 9 & Yes & Yes & No & No & No \\
\hline 13 & Male & 32 & Positive & 8 & 10 & Yes & No & No & No & No \\
\hline 14 & Male & 39 & Positive & 9 & $\frac{4}{4}$ & Yes & No & Yes & No & No \\
\hline 15 & Male & 38 & Positive & 10 & 10 & No & Yes & Yes & No & No \\
\hline 16 & Male & 39 & Positive & 8 & 11 & No & Yes & Yes & No & No \\
\hline 17 & Female & 38 & Positive & 8 & 5 & Yes & Yes & No & No & No \\
\hline 18 & Female & 39 & Positive & 9 & 4 & Yes & Yes & No & No & No \\
\hline 19 & Female & 31 & Positive & 2 & 5 & Yes & No & No & No & No \\
\hline 20 & Female & 40 & Positive & 2 & 14 & No & No & No & Yes & No \\
\hline 21 & Female & 38 & Positive & 14 & 5 & Yes & No & Yes & No & No \\
\hline 22 & Female & 30 & Positive & 8 & 9 & No & No & No & No & No \\
\hline 23 & Female & 31 & Positive & 9 & 9 & No & No & No & No & No \\
\hline 24 & Female & 47 & Positive & 9 & $\frac{1}{4}$ & No & No & Yes & No & No \\
\hline 25 & Female & 33 & Positive & 13 & 8 & Yes & Yes & Yes & Yes & Yes \\
\hline 26 & Female & 32 & Positive & 14 & 9 & Yes & Yes & Yes & Yes & Yes \\
\hline 27 & Female & 41 & Positive & 11 & 8 & Yes & Diabetic & Yes & Yes & Yes \\
\hline 28 & Female & 38 & Positive & 13 & 4 & Yes & Yes & Yes & Yes & Yes \\
\hline 29 & Female & 38 & Positive & 7 & 10 & Yes & Yes & Yes & Yes & Yes \\
\hline 30 & Female & 37 & Positive & 2 & 11 & Yes & Diabetic & Yes & Yes & Yes \\
\hline 31 & Female & 38 & Positive & 8 & 12 & Yes & Diabetic & Yes & Yes & Yes \\
\hline 32 & Female & 46 & Positive & 9 & 5 & Yes & Diabetic & Yes & Yes & Yes \\
\hline & & & & & 102 & & & & & \\
\hline
\end{tabular}

\begin{tabular}{|l|l|l|l|l|l|l|l|l|l|l|}
33 & FEMALE & 48 & POSITIVE & 14 & 4 & YES & YES & YES & YES & YES \\
\hline 34 & FEMALE & 48 & POSITIVE & 15 & 13 & YES & YES & YES & YES & YES \\
\hline 35 & FEMALE & 47 & POSITIVE & 9 & 14 & YES & DIABETIC & YES & YES & YES \\
\hline 36 & FEMALE & 49 & POSITIVE & 8 & 16 & YES & DIABETIC & YES & YES & YES \\
\hline 37 & FEMALE & 48 & POSITIVE & 9 & 15 & YES & DIABETIC & YES & YES & YES \\
\hline 38 & FEMALE & 51 & POSITIVE & 7 & 8 & YES & YES & YES & YES & YES \\
\hline 39 & FEMALE & 49 & POSITIVE & 8 & 9 & YES & YES & YES & YES & YES \\
\hline 40 & FEMALE & 48 & POSITIVE & 9 & 10 & YES & YES & YES & YES & YES \\
\hline 41 & FEMALE & 47 & POSITIVE & 10 & 8 & YES & DIABETIC & YES & YES & YES \\
\hline 42 & FEMALE & 48 & POSITIVE & 9 & 9 & YES & DIABETIC & YES & YES & YES \\
\hline 43 & FEMALE & 47 & POSITIVE & 9 & 10 & YES & YES & YES & YES & YES \\
\hline 44 & FEMALE & 32 & POSITIVE & 8 & 5 & NO & NO & NO & YES & NO \\
\hline 45 & FEMALE & 39 & POSITIVE & 8 & 8 & NO & NO & YES & YES & NO \\
\hline 46 & FEMALE & 41 & POSITIVE & 8 & 8 & YES & NO & NO & YES & NO \\
\hline 47 & FEMALE & 49 & POSITIVE & 7 & 9 & NO & NO & NO & YES & NO \\
\hline 48 & FEMALE & 48 & POSITIVE & 2 & 5 & NO & NO & YES & NO & NO \\
\hline 49 & FEMALE & 33 & POSITIVE & 14 & 5 & NO & YES & NO & NO & NO \\
\hline 50 & FEMALE & 41 & POSITIVE & 3 & 14 & NO & YES & NO & NO & NO \\
\hline
\end{tabular}



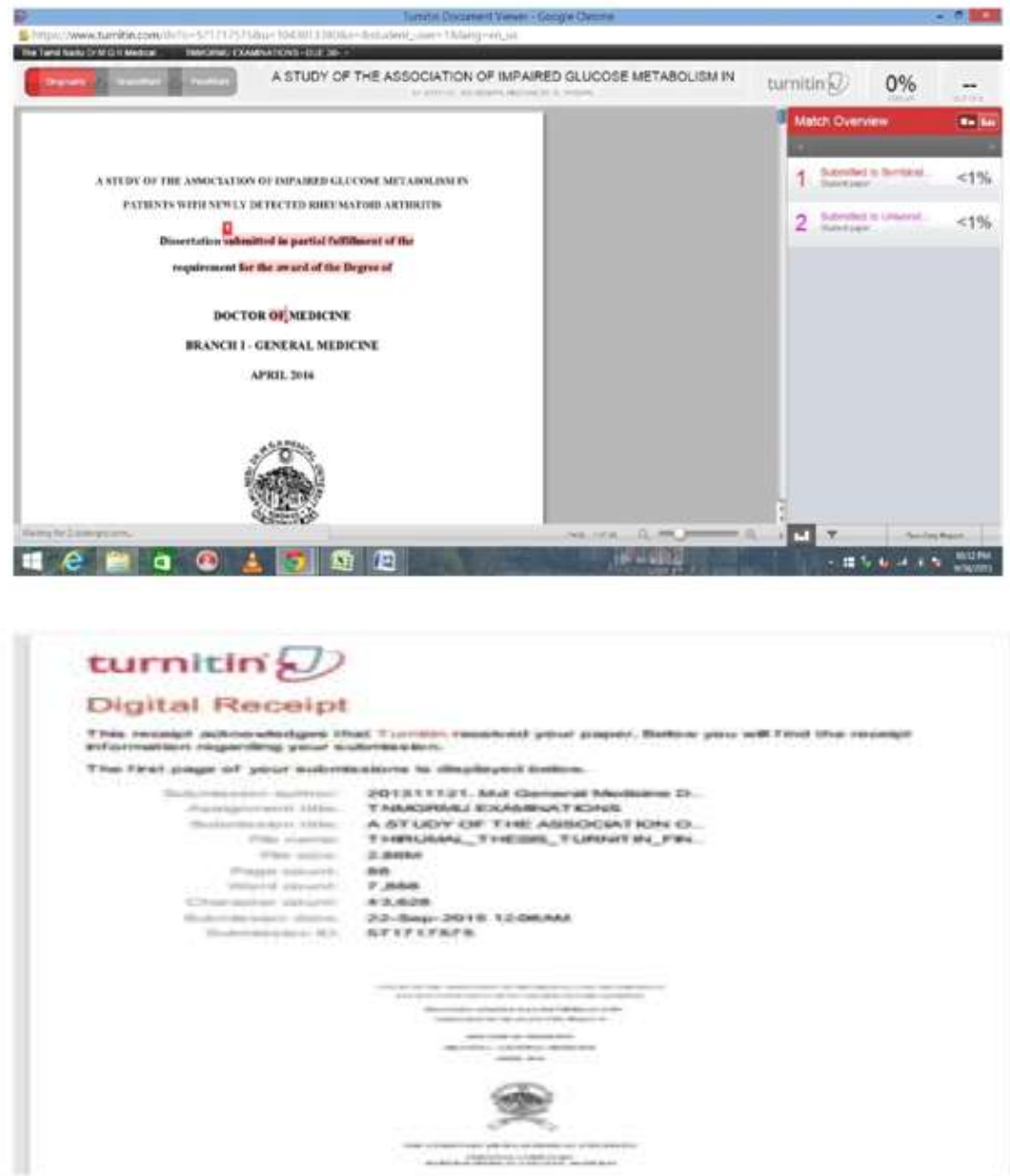